\title{
Isatin as a Strategic Motif for Asymmetric Catalysis
}

\author{
Somayeh Mohammadi, ${ }^{[\mathrm{a}]}$ Roghayeh Heiran, ${ }^{[\mathrm{a}]}$ Raquel P. Herrera, ${ }^{*[\mathrm{a}]}$ and Eugenia \\ Marqués-López ${ }^{*[a]}$
}

\section{Introduction}

3-Substituted-3-hydroxyindolin-2-ones have gained much attention from organic and medicinal chemists since this motif constitutes a core structure of a number of natural products ${ }^{[1]}$ and drug candidates, ${ }^{[2]}$ such as convolutamydines, ${ }^{[3]}$ diazonamides,${ }^{[4]}$ leptosin $\mathrm{D},{ }^{[5]} 3^{\prime}$ '-hydroxyglucoisatisin, ${ }^{[6]}$ witindolinone $\mathrm{C},{ }^{[7]}$ TMC$95,{ }^{[8]}$ celogentin $\mathrm{K},{ }^{[9]}$ dioxibrassinin ${ }^{[10]}$ (Figure 1 ), as well as several other pharmaceutically active compounds. ${ }^{[11]}$ The biological activity of these compounds is derived from their substituted group at C-3 position as well as the absolute configuration of the stereogenic center. ${ }^{[1 \mathrm{c}]}$<smiles>CSC[C@H]1NC(=O)[C@H]([C@H](C)[C@]2(O)C(=O)N(C)c3ccccc32)C(=O)N1</smiles>

$-\mathrm{OH}$ Maremycin A '.' $\mathrm{OH}$ Maremycin B<smiles>CC(=S)NCC1(O)C(=O)Nc2ccccc21</smiles>

Dioxibrassinin<smiles>[R]C1(O)C(=O)Nc2ccccc21</smiles>

3-substituted3-hydroxyindolin -2-ones<smiles>[M]OCCC1(O)C(=O)Nc2ccccc21</smiles>

Donaxaridine<smiles>CCN(CC)CCN1C(=O)[C@@](O)(c2ccccc2Cl)c2c1cc(C(N)=O)cc2C(F)(F)F</smiles>

SM-130686<smiles>[R]C1(O)C(=O)Nc2cc(Br)cc(Br)c21</smiles>

Convolutamydine

A: $\mathrm{R}=\mathrm{CH}_{2} \mathrm{COCH}_{3}$

B: $\mathrm{R}=\mathrm{CH}_{2} \mathrm{CH}_{2} \mathrm{Cl}$

C: $\mathrm{R}=\mathrm{CH}_{3}$

D: $\mathrm{R}=\mathrm{CH}=\mathrm{CH}_{2}$

$\mathrm{E}: \mathrm{R}=\mathrm{CH}_{2} \mathrm{CH}_{2} \mathrm{OH}$

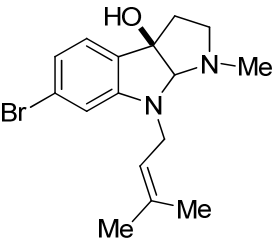

Flustraminol
Figure 1. Representative examples of active molecules containing 3substituted-3-hydroxyindolin-2-ones as core structure.

Therefore, the development of efficient and practical methods to synthesize such kind of compounds is of great importance and it is a current open area of research in asymmetric catalysis. ${ }^{[12]}$ One of the most straightforward approaches to enantiopure 3substituted-3-hydroxyindolin-2-ones is a catalytic nucleophilic addition of appropriate nucleophiles to readily available isatins, giving access to interesting molecular architectures with chiral centers. ${ }^{[13]}$ In many reported works an enantioselective organo- or a metal-catalyzed method have been used for the synthesis of these appealing structures. Herein, we would like to show representative examples of these catalytic strategies where an isatin derivative was a key reagent, reported since 2000 .

\section{Asymmetric organocatalysis}

\section{Enantioselective aldol reaction}

Aldol reaction is one of the most important and powerful method for $\mathrm{C}-\mathrm{C}$ bond formation in organic synthesis, and its asymmetric version has been broadly developed in the last decade. ${ }^{[14]}$ In this sense, catalytic enantioselective aldol reactions of aldehydes and ketones with isatins represent a direct approach to 3-alkyl-3hydroxyindolin-2-ones with a new chiral stereocenter.

The first enantioselective aldol reaction of acetone (2) with $\mathrm{N}$ alkylated isatins 1 was described by Tomasini and co-workers in $2005{ }^{[15,16]}$ Final desired products 4 with a new stereocenter with $(R)$-configuration were obtained with quantitative yields and good enantioselectivities (73-77\% ee) when $10 \mathrm{~mol} \%$ of dipeptide H-DPro-L- $\beta^{3}-\mathrm{hPhg}-\mathrm{OBn} 3$ was used as catalyst (Scheme 1). The reaction was performed with a high excess of acetone (90 equivalents) to favor the solubility of catalyst in this polar medium. The absolute configuration of proline skeleton seems to be decisive for the sign of the enantiomeric excess, and an accurate choice of the amino acid moiety in the second position was also indispensable to optimize the results. ${ }^{[17]}$

A synthetic application of this method was later used in the first enantioselective construction of $(R)$-convolutamydine $\mathrm{A}$ skeleton, a marine natural product, ${ }^{[3]}$ starting from 4,6dibromoisatin (Scheme 1). ${ }^{[18]}$ Enantiomerically enriched $(R)-5$ ( $50 \%$ yield, $97 \%$ ee) was obtained after elimination of the catalyst by filtration on silica, partial recrystallization in order to eliminate rac-5, and subsequent concentration of aqueous mother with a further recrystallization.

[a] S. Mohammadi. R. Heiran, Dr. R. P. Herrera, Dr. E. Marqués-López Departamento de Química Orgánica. Instituto de Síntesis Química y Catálisis Homogénea (ISQCH), CSIC-Universidad de Zaragoza. E-50009 Zaragoza, Spain. Fax: +34 976762075; Tel: +34 976762281

E-mail: raquelph@unizar.es, mmaamarq@unizar.es 
<smiles></smiles>
$\mathrm{R}^{1}=\mathrm{H}, \mathrm{Br} ; \mathrm{R}^{2}=\mathrm{H}, \mathrm{Me}, \mathrm{Et}, \mathrm{Bn}$

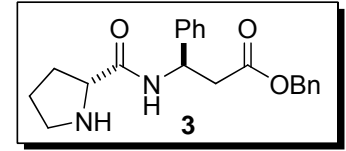<smiles>CC(=O)C[C@@]1(O)C(=O)Nc2cc(Br)cc(Br)c21</smiles>

quantitave yield, $68 \%$ ee (50\%, $97 \%$ ee, after recryst.)

Scheme 1. Enantioselective aldol reaction of isatin derivatives 1 with acetone (2) catalyzed by dipeptide 3 .

In an additional study, ${ }^{[19]}$ the same research group realized about the importance and influence of the presence of variable amounts of water in the previous explored cross-aldol reaction in terms of both reactivity and enantioselectivity. The results were consistent with earlier reported studies where small amounts of water could not only increase the reaction rate but also improve the enantioselectivity of the reaction, ${ }^{[20]}$ whereas a large excess of water could be detrimental for the process. ${ }^{[21]}$

After the first synthesis of $(R)$-convolutamydine $\mathrm{A}((R)-5)$, the synthesis of the opposite enantiomer in high yield $(99 \%, 45 \%$ after recrystallization) and moderate enantioselectivity $(60 \%$ ee, $87 \%$ ee after recrystallization) was reported by Xiao and coworkers using L-proline-derived bifunctional organocatalyst $6 .{ }^{[22]}$ Interestingly, the authors also examined the ability of this catalyst in the aldol reaction of isatins with non-symmetric ketones such as 2-butanone (7) (Scheme 2), and not only with acetone (2). ${ }^{[23]}$ This process was also efficient, providing the aldol adducts 8 in excellent chemical yields (up to 99\%) with good enantioselectivities $(70-75 \%$ ee). The reaction exhibited high regioselectivity (up to $12: 1,8: 9$ ), and afforded the products of C$\mathrm{C}$ bond formation through the less substituted C1-position of 2butanone (7), as the major regioisomer $\mathbf{8}$, versus minor isomer $\mathbf{9}$.
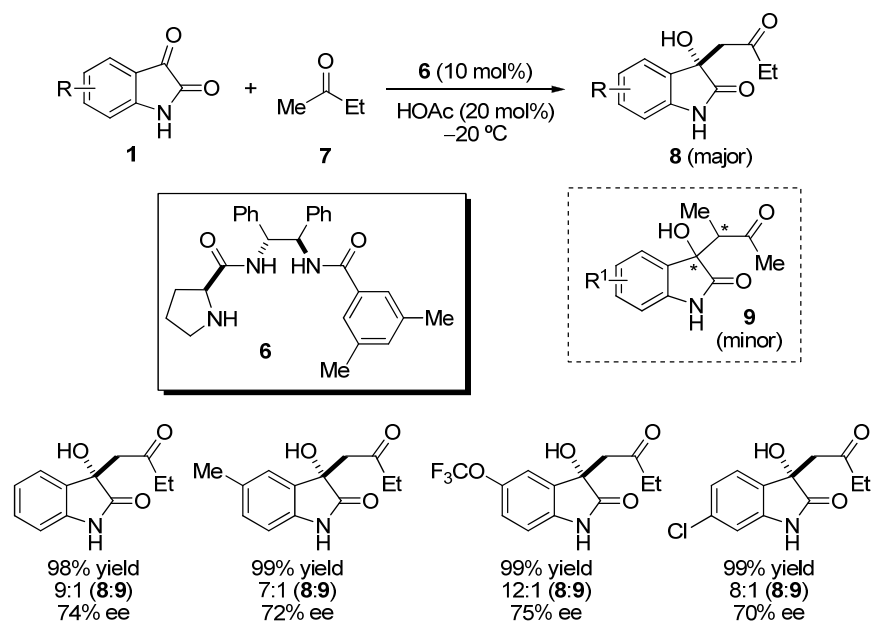

Scheme 2 Enantioselective aldol reaction of isatins 1 with 2-butanone (7).
The authors hypothesized that the absolute $(S)$-configuration obtained in final adducts, in the case of reaction with acetone (2), could be governed by enantiofacial discrimination between the geometry of the active specie catalyst-enamine and the orientation of isatin, as represented in Figure 2. The proposal of the authors was consistent with previous transition state models where L-proline was involved. ${ }^{[24]}$

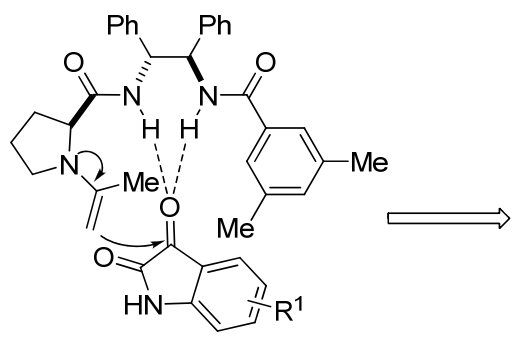<smiles>CC(=O)CC1(O)C(=O)Nc2ccccc21</smiles>

Figure 2. Plausible TS model for aldol reaction using catalyst 6

Kočovský group disclosed that vicinal amino alcohols efficiently promoted the asymmetric cross-aldol reaction of isatins with acetone (2). ${ }^{[25]}$ Leucinol (10) was identified as the most effective catalyst exhibiting excellent reactivity and enantioselectivity under the optimal reaction conditions. With this strategy, the synthesis of both enantiomers of convolutamydine A (5) was addressed using $20 \mathrm{~mol} \%$ of L- or D-leucinol (10). More interesting was the uncommon mechanism envisioned by the authors to explain the role of the catalyst in the transition state of this process (Figure 3 ).

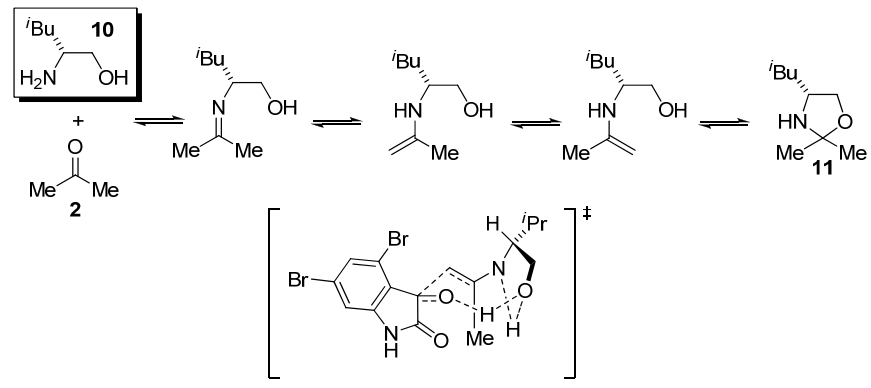

Figure 3. Equilibrium to give oxazolidine $\mathbf{1 1}$ and proposed TS for aldol reaction using catalyst D-leucinol (10).

The authors invoked the formation of oxazolidine $\mathbf{1 1}$ as the active specie in the catalytic cycle, and as a proof of fact the same effectiveness was accomplished performing the reaction with preformed compound $\mathbf{1 1}$. The key role of the hydroxy group in the catalyst was demonstrated with the use of $O$-methylated leucinol since poorer enantioselectivities were obtained under the same reaction conditions, which is also consistent with the required formation of oxazolidine $\mathbf{1 1}$. This also suggests that hydrogen bonding between the keto group of isatin 1 and the enamine specie could be a prerequisite for the highly enantioselective process, as represented in TS (Figure 3).

$\mathrm{N}$-(2-Thienylsulfonyl)prolinamide $\mathbf{1 2}$ was found to work as an efficient catalyst for the synthesis of various convolutamydine $A$ derivatives by using only $0.5 \mathrm{~mol} \%$, the lowest catalyst loading used in this process. ${ }^{[26,27]}$ In a premature explanation, the authors suggested the important role played by the amide proton in the enantioselectivity of the process and that the reaction 
preferentially proceeds through the anti-trans-TS to give $(R)-5$, versus the syn-trans-TS, which would afford (S)-5 enantiomer and would be destabilized by steric repulsions as depicted in Figure 4.
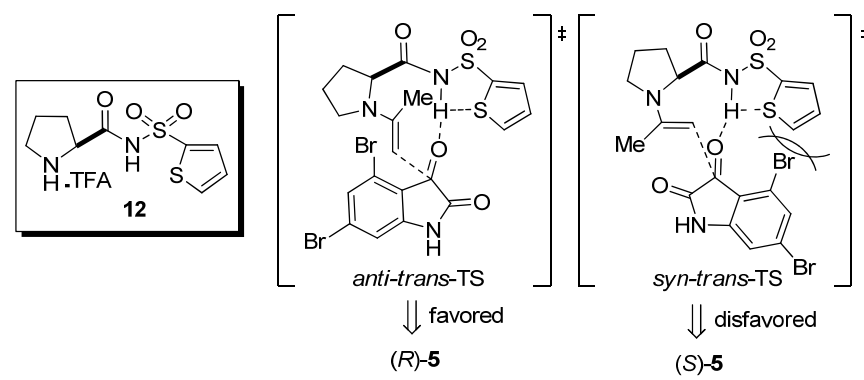

Figure 4. Proposed TS for the synthesis of $(R)$-convolutamydine A (5) using catalyst 12.

Zhao and co-workers applied cinchona derivative 14 as an effective catalyst for the synthesis of 3-alkyl-3-hydroxyindolin-2ones 15 (Schemes 3). ${ }^{[28]}$ They envisioned the possibility of generating an enolate from unactivated ketones with a basic moiety in the catalyst structure in order to favor the formation of the active specie. This method is complementary to the enaminebased organocatalyzed aldol reactions developed using chiral secondary or primary amines, ${ }^{[29]}$ and is appropriate in cases where the formation of the enamine could be difficult. Between the remarkable results obtained, acetophenone was used as nucleophile in this asymmetric aldol reaction with isatins for the first time, and excellent results were also reached for $\alpha, \beta$ unsaturated ketones.<smiles>[R1]c1ccc2c(c1)C(=O)C(=O)N2</smiles>

$\mathrm{R}^{1}=\mathrm{H}, 4-\mathrm{Cl}, 4-\mathrm{Br}, 5-\mathrm{F}$, $6-\mathrm{Br}, 5,7-\mathrm{di}-\mathrm{Br}$

$\mathrm{R}=\mathrm{Me}, \mathrm{Ph}, 1-\mathrm{Np}, \mathrm{MeCH}=\mathrm{CH}$ $\mathrm{PhCH}=\mathrm{CH}, \mathrm{H}$<smiles>[R]C(=O)C[C@]1(O)C(=O)Nc2cc[R1]cc21</smiles>

15

17 examples $70-99 \%$ yield $73-97 \%$ ee

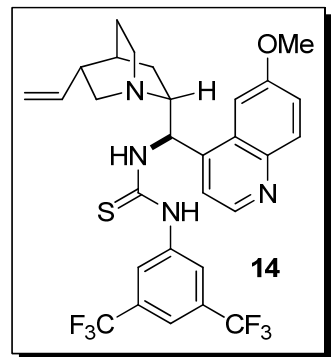

Scheme 3. Cinchona derivative 14 catalyzed enantioselective aldol reaction of isatins 1 with ketones 13

According to the obtained results a possible mechanism is proposed in Figure $5 .^{[30]}$ The first step would be the formation of the enamine by deprotonation with the tertiary amine in the catalyst backbone. On the other hand, the catalyst could play a dual role activating the isatin by two hydrogen bonds formed with the thiourea moiety, which would also direct the approach of isatin to the enolate. Among the two possible orientations of isatin depicted in Figure 5, the re face orientation is favored avoiding the steric interaction between the isatin benzene ring and the enolate in the TS2. Moreover, TS1 would lead to the observed major $(R)$-enantiomer.

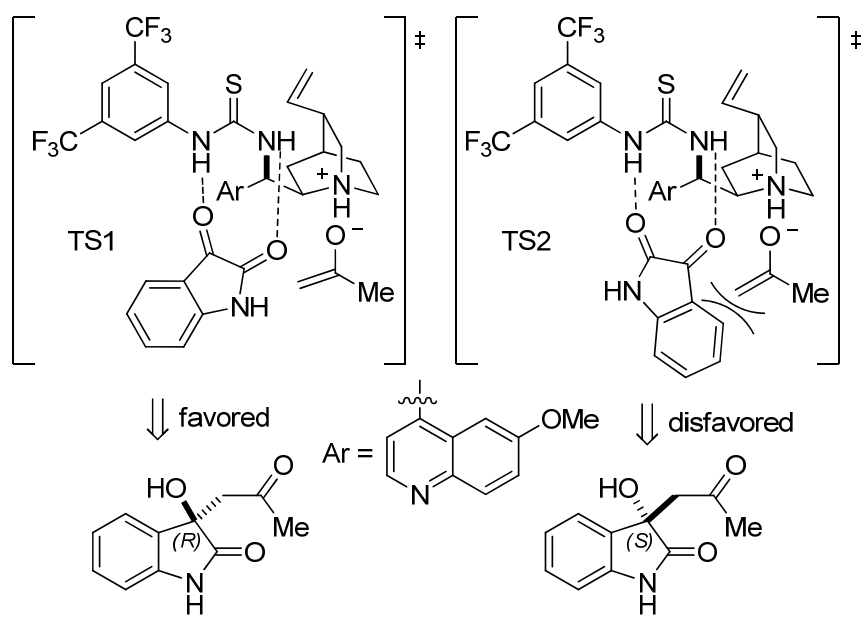

Figure 5. Proposed TS for the aldol reaction of isatin and acetone (2) with cinchona derivative catalyst 14

Synthesis of 3-cycloalkanone-3-hydroxy-2-oxindoles 16 is highly desired for medicinal chemistry because of their potential biological activity. ${ }^{[31]}$ Recently, heterogeneous organocatalyst chitosan 17, used as green and recyclable catalyst, has been introduced to afford, by the first time, direct asymmetric aldol reaction in water between cyclohexanone and isatin with moderate results (Figure 6). ${ }^{[32]}$ However, better results were achieved with primary-tertiary diamine-Brønsted acid catalyst 18/TFA (10 mol\%) introduced as an efficient promoter to give 3cyclohexanone-3-hydroxy-2-oxindoles $16 .{ }^{[33]}$ Cyclohexanone was also explored in the catalytic asymmetric aldol reaction with isatins using carbohydrate-derived amino alcohol 19 as catalyst (Figure 6) ${ }^{[34]}$ In that report, the reaction of various isatins with acetone, acetophenone and cyclohexanone was investigated under the optimal reaction conditions. According to the obtained results, the primary amino group of the catalyst was found to be very important for the activity and selectivity of the reaction.

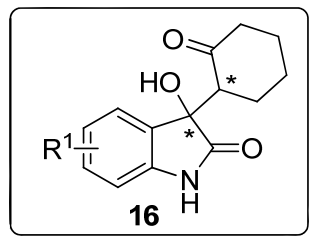

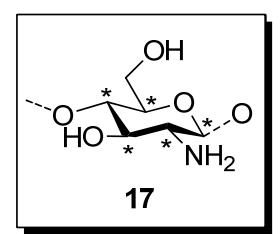

$86 \%$ yield 98:2 (anti:syn) $77 \%$ ee

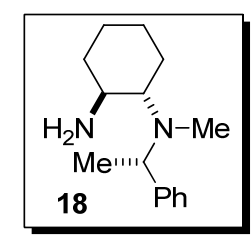

up to $92 \%$ yield up to $99: 1$ (syn:anti) up to $99 \%$ ee

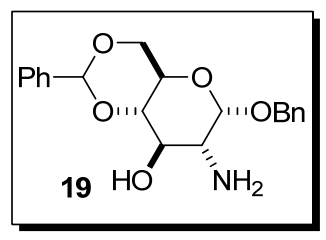

$99 \%$ yield d.r. $81 \%$

Figure 6. Catalysts 17-19 used for the synthesis of 3-cyclohexanone-3-hydroxy2-oxindoles 16. 
Nakamura's group applied prolinamide $\mathbf{1 2}$ in the first enantioselective aldol reaction between linear aldehydes 20 and isatins 1 affording final adducts 21 with high yields and enantioselectivities (Scheme 4). ${ }^{[35]}$ The efficacy of the developed methodology was successfully demonstrated achieving the first enantioselective synthesis of convolutamydine $E(22)$, and the synthesis of enantiopure convolutamydine B (23), reached by a subsequent derivatization of 22 (Scheme 4).<smiles>[Y]c1cc([X])c2c(c1)NC(=O)C2=O</smiles>

$\mathrm{X}, \mathrm{Y}=\mathrm{H}, \mathrm{Br}, \mathrm{Cl}$, I $\mathrm{R}=\mathrm{H}, \mathrm{Me}, \mathrm{Et}, \mathrm{PhCH}_{2}$<smiles>O=C1Nc2cc(Br)cc(Br)c2[C@]1(O)CCO</smiles>

(R)-Convolutamydine $\mathrm{E}$ (22) $94 \%$ yield, $92 \%$ ee

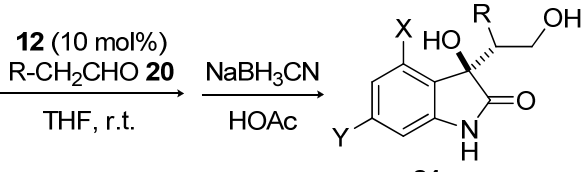

21

$\mathrm{R} \neq \mathrm{H}, 3$ examples $\mathrm{R}=\mathrm{H}, 7$ examples $80-98 \%$ yield $\quad 60-99 \%$ yield up to $>98: 2$ d.r. $\quad$ up to $99 \%$ ee $90-98 \%$ ee<smiles>O=C1Nc2cc(Br)cc(Br)c2C1(O)CCCl</smiles>

(R)-Convolutamydine $\mathrm{B}$ (23) $87 \%$ yield, $92 \%$ ee ( $98 \%$ ee, after recryst.)

Scheme 4. Synthesis of enantiopure convolutamydine $E$ (22) and convolutamydine B (23).

Independently, Wang and co-workers disclosed the reactivity shown with $\alpha$-branched aldehydes 24 in the same cross-aldol reaction with isatins ${ }^{[36]}$ complementing in this way the previous reported work using lineal aldehydes (Scheme 5). ${ }^{[35]}$ Various chiral catalysts were examined in the preliminary screening to explore the viability of the process and among them (S)pyrrolidinetetrazole $\mathbf{2 5}$ afforded desired product $\mathbf{2 6}$ with promising results.<smiles>[R]N1C(=O)C(=O)c2c[R1]#ccc21</smiles><smiles>O=Cc1[R]cccc1</smiles>
24

$\mathrm{R}^{1}=4-\mathrm{Me}, 4-\mathrm{Br}, 5-\mathrm{F}$, $5-\mathrm{Cl}, 6-\mathrm{Br}, 4,6-\mathrm{di}-\mathrm{Br}, 7-\mathrm{Cl}$ $\mathrm{R}^{2}=\mathrm{H}, \mathrm{Bn}$ $\mathrm{R}^{3}=\mathrm{H}, \mathrm{Me},{ }^{n} \mathrm{Bu},-\left(\mathrm{CH}_{2}\right)_{4}^{-}$ $\mathrm{R}^{4}=\mathrm{Me},{ }^{n} \mathrm{Bu}$

Scheme 5. (S)-Pyrrolidinetetrazole 25 catalyzed cross-aldol reaction of isatins 1 with $\alpha$-branched aldehydes 24 .

In the same context, Hayashi and co-workers ${ }^{[37]}$ introduced 4hydroxydiarylprolinol $\mathbf{2 7}$ as an efficient catalyst for asymmetric aldol reaction of isatin derivatives with acetaldehyde. The reaction was performed in DMF in the presence of $\mathrm{ClCH}_{2} \mathrm{CO}_{2} \mathrm{H}$ as additive. ${ }^{[38]}$ The obtained chiral diols 28 were key synthetic intermediates in the preparation of some natural products such as convolutamydine $E(\mathbf{2 2})$, indole fragment of madindoline $A$ and $B$ (29) ${ }^{[39]}$ and CPC-1 (30) ${ }^{[40]}$ (Figure 7).
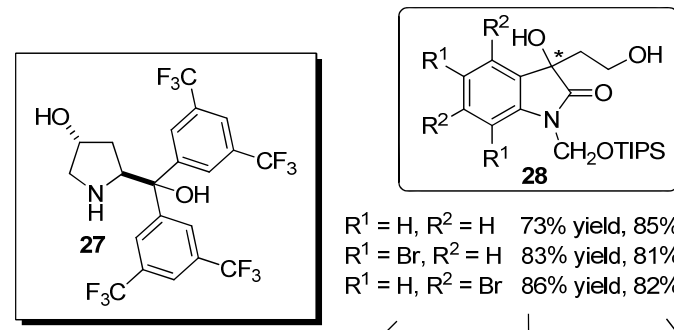

$\mathrm{R}^{1}=\mathrm{H}, \mathrm{R}^{2}=\mathrm{H} \quad 73 \%$ yield, $85 \%$ ee $(R)$

$\mathrm{R}^{1}=\mathrm{Br}, \mathrm{R}^{2}=\mathrm{H} \quad 83 \%$ yield, $81 \%$ ee $(R)$

$\mathrm{R}^{1}=\mathrm{H}, \mathrm{R}^{2}=\mathrm{Br} \quad 86 \%$ yield, $82 \%$ ee $(S)$

(R)-Convolutamydine $\mathrm{E}(22)$
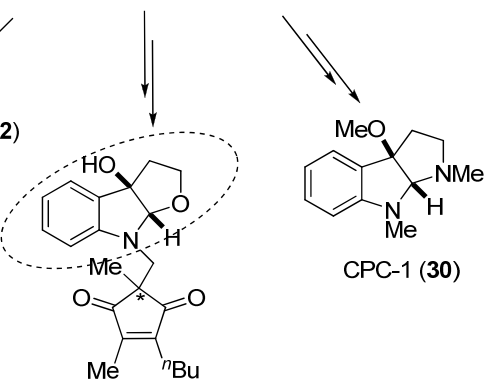

CPC-1 (30)

Madindoline A and B (29)

Figure 7. Natural products synthesized from fragment 28.

According to the obtained results, the authors suggested that the proton of the hydroxy group of the diarylmethanol moiety in catalyst 27 could coordinate the carbonyl group of isatin $\mathbf{1}$ through modes $A$ and $B$ depending on the substituent in the isatin molecule and explaining in this sense, the enantioface selection observed (Figure 8). That is, when the substituent at C5 of isatin is small, mode A would be suitable affording the $(R)$-isomer, but in case of a larger substituent like a bromine atom, mode $B$ would be favorable obtaining $(S)$-isomer.<smiles></smiles>

(Mode $\mathrm{A}) \Longrightarrow(R)$-isomer<smiles>[R]N1C(=O)C(=O)c2c(Br)cccc21</smiles>

(Mode B) $\Longrightarrow(S)$-isomer
Figure 8. Coordination modes of $\mathrm{OH}$ catalyst 27 to isatin derivatives 1.

For a synthetic pathway to obtain 3-hydroxyoxindoles 32 with a gem-difluoro-methylene group that can increase the lipophilicity, metabolic stability and bioavailability of the compounds, ${ }^{[41]}$ Zhou group reported the first organocatalytic enantioselective aldol reaction route between difluoroenoxysilane $\mathbf{3 1}$ and isatin $\mathbf{1}$, using THF as solvent at $0{ }^{\circ} \mathrm{C}$ (Scheme 6$) .{ }^{[42]}$

Between the different bifunctional (thio)urea catalysts examined, the best results were reached with quinine derived urea catalyst $\mathbf{3 3}$ affording final products $\mathbf{3 2}$, in most cases, with very good enantioselectivity $(88-95 \%$ ee). Here, urea catalyst $\mathbf{3 3}$ plays a dual role in the acceleration of the reaction; (1) activating the difluoroenoxysilane $\mathbf{3 1}$ by the tertiary amine in the quinine backbone, (2) activating isatin 1 by the urea part of the catalyst through $\mathrm{H}$-bonding interaction as shown in Figure 9. 


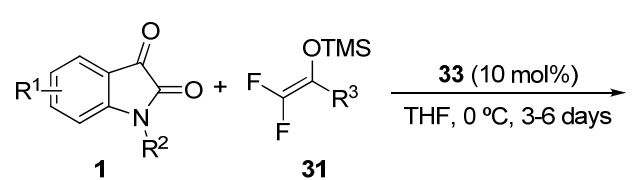

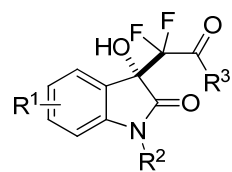

32

16 examples

$\begin{array}{lc}\mathrm{R}^{1}=\mathrm{H}, 5-\mathrm{Cl}, 5-\mathrm{Br}, 5-\mathrm{F}, 5-\mathrm{OMe}, 5-\mathrm{Me}, 4,6-\text { di-Me } & 16 \text { examples } \\ \mathrm{R}^{2}=\mathrm{H}, \mathrm{Me} & 85-90 \% \text { yield } \\ & 88-95 \% \text { ee }\end{array}$

$\mathrm{R}^{3}=\mathrm{Ph}, 4-\mathrm{OMeC}_{6} \mathrm{H}_{4}, 3-\mathrm{OMeC}_{6} \mathrm{H}_{4}$,

4- $\mathrm{MeC}_{6} \mathrm{H}_{4}, 3-\mathrm{MeC}_{6} \mathrm{H}_{4}, 4-\mathrm{ClC}_{6} \mathrm{H}_{4}$ 3- $\mathrm{ClC}_{6} \mathrm{H}_{4}$, 2-naphthyl, 2-thienyl<smiles>COc1ccc2c(C)ccnc2c1</smiles>

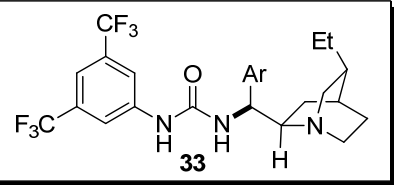

Scheme 6. Aldol reaction of isatins $\mathbf{1}$ and difluoroenoxysilane $\mathbf{3 1}$ in the presence of bifunctional urea catalyst $\mathbf{3 3}$.

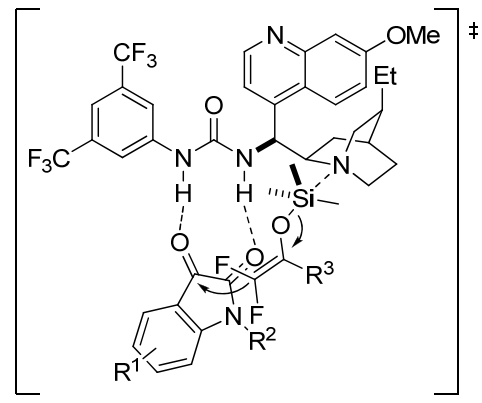

Figure 9. Proposed TS for aldol reaction using urea catalyst 33.

Remarkably, this protocol was efficiently used for the with even greater biological activities, using catalyst 14 (Scheme $7)$.

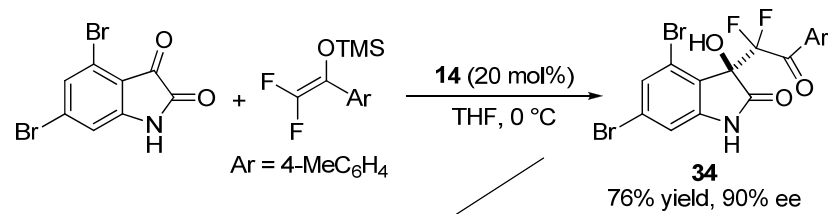

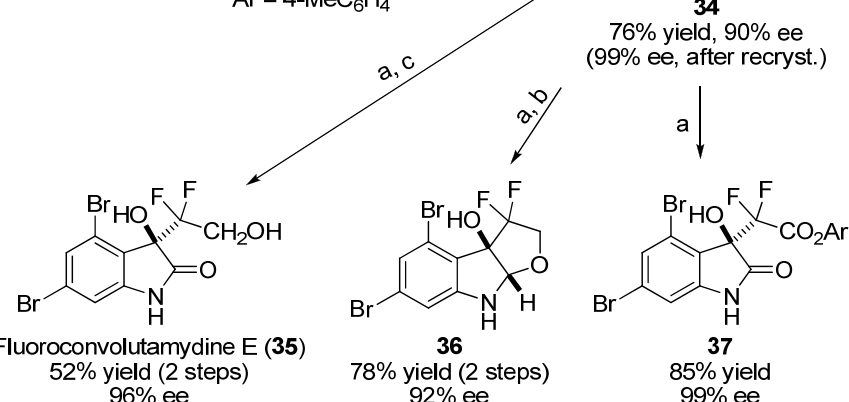

a) MCPBA, $\mathrm{CH}_{2} \mathrm{Cl}_{2} / \mathrm{HFIP}$, buffer $\mathrm{pH}=7.6$

b) $\mathrm{NaBH}_{4}$ (5 eq.), $\mathrm{THF} / \mathrm{H}_{2} \mathrm{O}(9: 1 \mathrm{v} / \mathrm{v})$, r.t.

c) $\mathrm{NaBH}_{4}$ (1 eq.), $\mathrm{MeOH}, 0^{\circ} \mathrm{C}$

Scheme 7. Synthesis of difluoro analogues of convolutamydine 34-37.

\section{Enantioselective Morita-Baylis-Hillman reaction}

The Morita-Baylis-Hillman (MBH) reaction is one of the most synthetically useful reactions between the $\alpha$-position of an synthesis of the difluoro analogues of convolutamydine 34-37, activated alkene and a carbonyl group of aldehyde or ketone, in molecules, which are important intermediates in a wide variety of fields. ${ }^{[43]}$

The enantioselective version of this reaction for aldehydes and imines has been explored using different catalysts such as chiral amines ${ }^{[44]}$ and phosphines. ${ }^{[45]}$ However, the use of activated ketones as suitable electrophile for this reaction has been less investigated, ${ }^{[46]}$ even when $\mathrm{MBH}$ products from ketones such as isatin would allow the preparation of chiral tertiary alcohols, which are useful building blocks and valuable synthetic intermediates. ${ }^{[4]}$

The first organocatalytic enantioselective example of this reaction was reported by Zhou and co-workers in 2010. They employed Hatakeyama's catalyst, $\beta$-iso-cupreidine $\mathbf{3 8}$ in an elegant reaction between isatins 1 and acrolein (39) leading to 3substituted-3-hydroxy-2-oxindoles $\mathbf{4 0}$ in very good yield (up to $97 \%$ ) and with excellent enantioselectivities (up to $98 \%$ ee) (Scheme 8 ). ${ }^{[48]}$ The aldehyde group present in final products 40 is valuable for further synthetic transformations.

$\mathrm{R}^{1}, \mathrm{R}^{2}=\mathrm{Cl}, \mathrm{Br}, \mathrm{F}, \mathrm{Me}, \mathrm{MeO}$

$\mathrm{R}^{3}=\mathrm{H}, \mathrm{Cl}$ $\mathrm{CF}_{3}, \mathrm{NO}_{2}$

$\mathrm{R}^{4}=\mathrm{H}, \mathrm{Me}, \mathrm{Bn}$

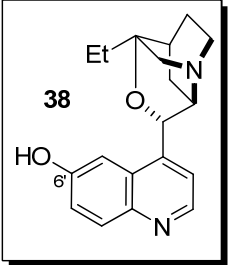<smiles>[R]c1cc2c(c([R])c1[R])N([R4])C(=O)[C@]2(O)C(=C)CC</smiles>

23 examples up to $97 \%$ yield up to $98 \%$ ee the presence of nucleophilic catalyst for producing multifunctional

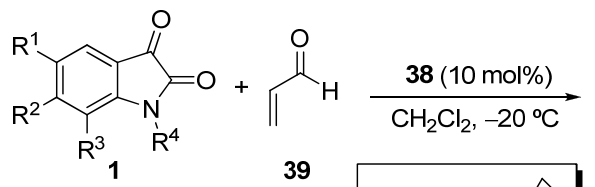

Scheme 8. Enantioselective $\mathrm{MBH}$ reaction catalyzed by $\beta$-iso-cupreidine 38 using acrolein 39.

After this pioneering example, $\beta$-iso-cupreidine catalyst $\mathbf{3 8}$ has also displayed remarkable catalytic effect in two similar methodologies directed toward the synthesis of MBH adducts $\mathbf{4 2}$ and $\mathbf{4 4}$ by reaction of isatins 1 with 1-naphthyl $(\mathbf{4 1})^{[49]}$ or benzyl $(43)^{[50]}$ acrylate respectively, in high yields and with excellent enantioselectivities (Scheme 9). Remarkably, opposite absolute configuration in final products $\mathbf{4 2}$ and $\mathbf{4 4}$ is observed using the same enantiomeric form of the catalyst 38.
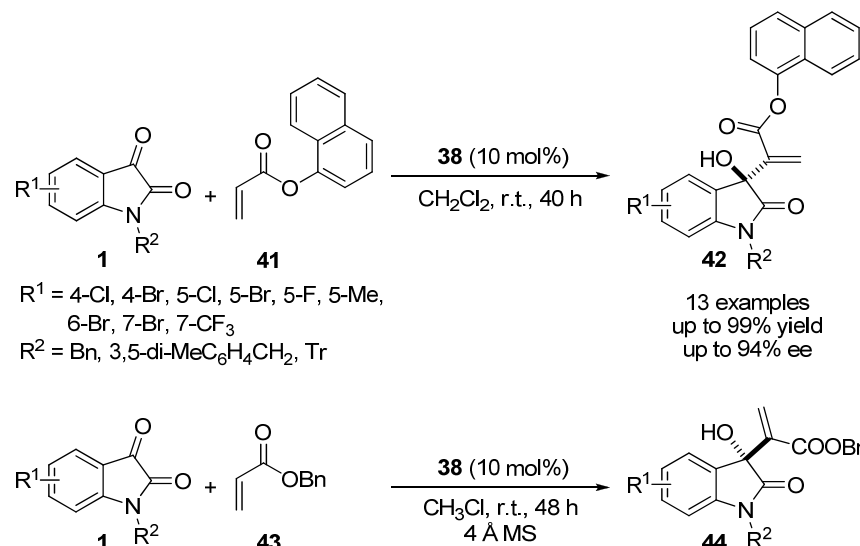

$\mathrm{R}^{1}=\mathrm{H}, 5-\mathrm{Cl}, 5-\mathrm{Br}, 5-\mathrm{F}, 5-\mathrm{Me}, 5-\mathrm{NO}_{2}$

$5-\mathrm{OMe}, 7-\mathrm{Cl}, 7-\mathrm{F}, 5,7-\mathrm{di}-\mathrm{Me}$

$\mathrm{R}^{2}=\mathrm{Me}, \mathrm{Ph}, \mathrm{Bn}, 4-\mathrm{MeOC}_{6} \mathrm{H}_{4}, 4-\mathrm{MeOC}_{6} \mathrm{H}_{4} \mathrm{CH}_{2}$
16 examples up to $96 \%$ yield up to $96 \%$ ee 
Scheme 9. Enantioselective MBH reaction of isatins 1 with acrylates $\mathbf{4 1}$ and $\mathbf{4 3}$ catalyzed by $\beta$-iso-cupreidine $\mathbf{3 8}$.

In order to explain the enantioselectivity obtained in the final products and to gain insight into the mechanism of this process, $\mathrm{Lu}$ and co-workers investigated the potential role played by the $\mathrm{C} 6^{\prime}-\mathrm{OH}$ of $\beta-\mathrm{ICD} 38$. Thus, $\beta$-isocinchonine without the free phenolic hydroxy group was prepared and applied in the reaction. The results indicated that the $\mathrm{C}^{\prime}-\mathrm{OH}$ group is critical for inducing excellent enantioselectivity and can contribute to the overall rate of the reaction. In the proposed mechanism depicted in Scheme $10 \beta$-ICD 38 shows two vital roles: (1) nucleophilic addition of $\beta$ ICD to the acrylate acting as Lewis base catalyst, (2) stabilizing the transition state by facilitating the proton transfer step via its participation in an intramolecular proton relay process with the isatin (intermediate 46).

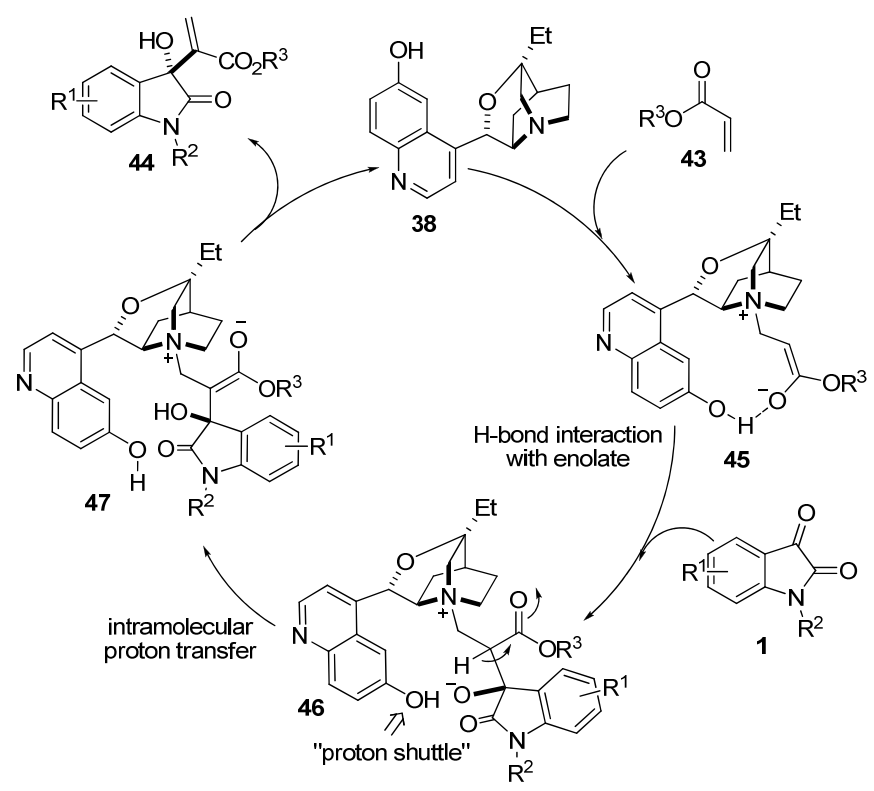

Scheme 10. Plausible mechanism of $\mathrm{MBH}$ reaction in the presence of $\beta-\mathrm{ICD} 38$.

Chiral phosphines have been also used as catalysts for this reaction. For example, $\mathrm{Wu}$ and co-workers used phosphinethiourea 48 and phosphine-squaramide 49 , acting both as bifunctional catalyst through nucleophilic activation by the tertiary phosphine moiety and electrophilic activation by hydrogenbonding with $\mathrm{NH}$ groups of the thiourea and squaramide. ${ }^{[51]}$ Although, lower enantiomeric excesses (up to $69 \%$ ee) were obtained in comparison with those previously reported, 3hydroxyl-2-oxindole derivatives $\mathbf{5 1}$ were obtained in excellent yields (up to $99 \%$ ) in the presence of $10 \mathrm{~mol} \%$ of catalyst 48 (Scheme 11). More recently, the same research group designed a new chiral bifunctional phosphine organocatalyst to extend the study of this $\mathrm{MBH}$ reaction. ${ }^{[52]}$ Novel organocatalyst 49 bearing squaramide moiety as $\mathrm{H}$-bond donor instead of a thiourea group, was confirmed to be efficient for this process, leading to high yields (up to $99 \%$ ) and appealing enantioselectivities (up to $99 \%$ ee after recrystallization) in the presence of a very low catalytic charge (2 mol\%) although with longer reaction time (Scheme 11).
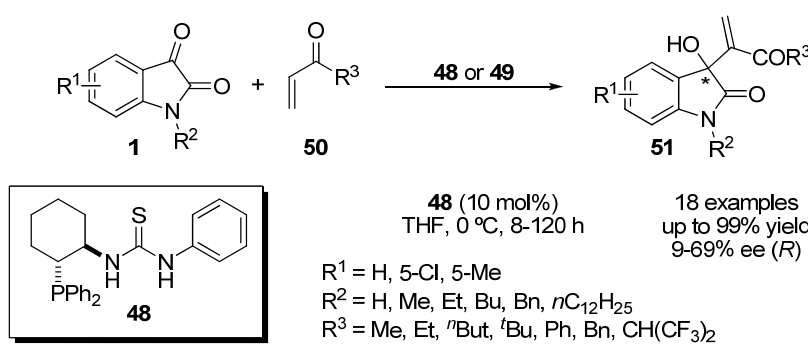
$\begin{array}{cr}\mathbf{4 8}(10 \mathrm{~mol} \%) & 18 \text { examples } \\ \text { THF, } 0^{\circ} \mathrm{C}, 8-120 \mathrm{~h} & \text { up to } 99 \% \text { yiel }\end{array}$
$\mathrm{R}^{1}=\mathrm{H}, 5-\mathrm{Cl}, 5-\mathrm{Me}$
$\mathrm{R}^{2}=\mathrm{H}, \mathrm{Me}, \mathrm{Et}, \mathrm{Bu}, \mathrm{Bn}, n \mathrm{C}_{12} \mathrm{H}_{25}$
$\mathrm{R}^{3}=\mathrm{Me}, \mathrm{Et},{ }^{n} \mathrm{But},{ }^{\mathrm{t}} \mathrm{Bu}, \mathrm{Ph}, \mathrm{Bn}, \mathrm{CH}\left(\mathrm{CF}_{3}\right)_{2}$

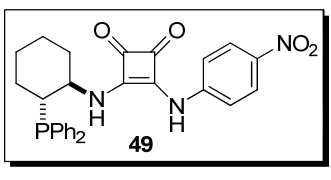

$$
\begin{aligned}
& 49(2 \mathrm{~mol} \%) \begin{array}{c}
18 \text { examples } \\
\text { up to } 99 \% \text { yield }
\end{array} \\
& \text { AcOEt, } 25^{\circ} \mathrm{C}, 1.5-7 \text { days } 71-99 \% \text { ee }(\mathrm{S}) \\
& \mathrm{R}^{1}= \mathrm{H}, 4-\mathrm{Cl}, 4-\mathrm{Br}, 5-\mathrm{F}, 5-\mathrm{Cl}, 5-\mathrm{Br}, \\
& 6-\mathrm{Br}, 7-\mathrm{Br}, 5-\mathrm{Me}, 5-\mathrm{MeO}, 7-\mathrm{Me} \\
& \mathrm{R}^{2}=\mathrm{Me},{ }^{n} \mathrm{Bu}, \mathrm{Bn} \\
& \mathrm{R}^{3}=\mathrm{Me}, \mathrm{Et},{ }^{n} \mathrm{Bu},{ }^{t} \mathrm{Bu}, \mathrm{Ph}, \mathrm{Bn}
\end{aligned}
$$

Scheme 11. MBH reaction catalyzed by phosphine-thiourea 48 , and phosphinesquaramide 49 .

\section{Enantioselective Friedel-Crafts reaction}

The use of Friedel-Crafts alkylation reactions has received considerable attention for preparation of highly functionalized aromatic compounds by $\mathrm{C}-\mathrm{C}$ and $\mathrm{C}-\mathrm{N}$ bond formation, which can produce important building blocks for pharmaceutically applicable compounds. ${ }^{[53]}$ To form optically active compounds based on Friedel-Crafts alkylation reactions, different research groups have reported various chiral catalysts such as chiral Lewis acids, ${ }^{[53 a, b, e]}$ chiral Brønsted acids ${ }^{[53 c]}$ based on non-covalent interactions between catalyst and reagents, and chiral primary or secondary amines, ${ }^{[53 \mathrm{~d}, \mathrm{f}]}$ based on covalent interactions to form an iminium intermediate.

Although one of the most studied enantioselective approaches for the synthesis of 3-substituted-3-hydroxyindolin-2ones involves asymmetric Friedel-Crafts reaction with isatins, scarce organocatalytic methods have been reported so far in the literature for this purpose. ${ }^{[54]}$ The first enantioselective synthesis of 3-hydroxyoxindoles via this approach was developed by Wang, $\mathrm{Li}$ and co-workers in 2010 using isatin $\mathbf{1}$ and indole $\mathbf{5 2}$ as nucleophile in the presence of cupreine (53) as promising catalyst under mild reaction conditions. ${ }^{[55]}$ It is noteworthy that integration of an indole moiety into an oxindole scaffold produces 3-indolyl-3hydroxy-2-oxindole $\mathbf{5 4}$ that are promising substrates for the study of their biological activity, as well as useful synthetic intermediates for drug candidates and alkaloids (Scheme 12).

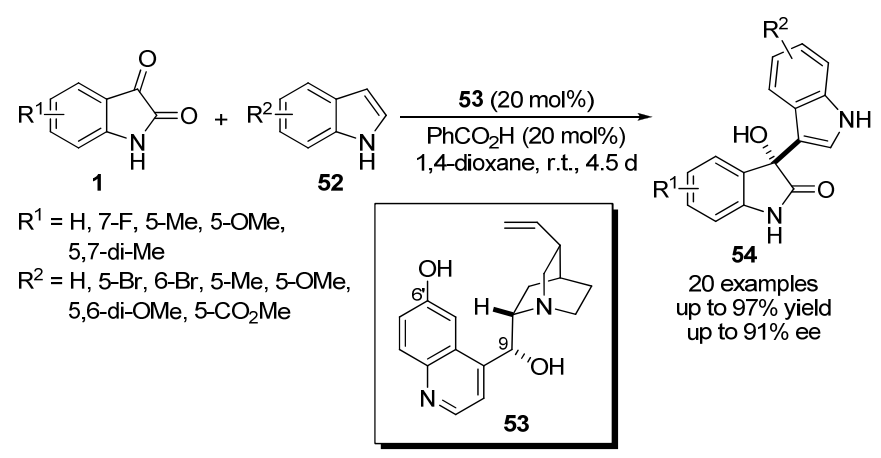

Scheme 12. Enantioselective Friedel-Crafts reaction of isatins $\mathbf{1}$ with indoles $\mathbf{5 2}$ catalyzed by cupreine (53). 
The feasibility of the process was examined with various catalysts, between them diverse cinchona alkaloids. From the results was envisioned that 6 '-OH group on the cinchona skeleton played an important role in determining the stereochemical course and the rate of the reaction. This fact was confirmed by comparison of catalysts without the 6'-OH group in the structure, or with a 6'-OMe moiety, with the cupreine (53), which afforded the best results. In order to explain the observed stereochemistry a tentative transition state is proposed in Figure 10, where catalyst $\mathbf{5 3}$ plays a dual function in the activation of substrates. On one hand, both $\mathrm{OH}$ groups (6' and 9) would interact with the carbonyl groups of isatin, while the quinuclidine tertiary amine would drive the indole for the attack over the re face of the ketone moiety of the isatin, delivering product $\mathbf{5 4}$ with (S)-configuration, determined by single crystal X-ray analysis.

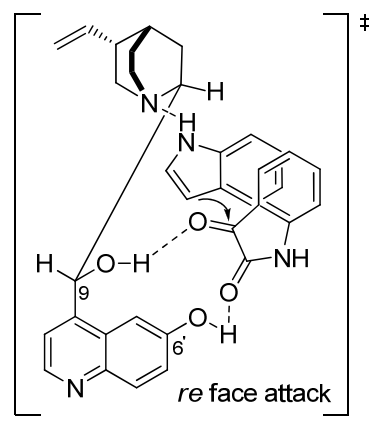

Figure 10. Proposed model for the cupreine (53) catalyzed enantioselective Friedel-Crafts alkylation reaction.

At the same time, Chimni and co-workers published a successful organocatalytic asymmetric Friedel-Crafts alkylation reaction for the synthesis of optically active 3-indolyl-3-hydroxy-2oxindoles 54 under very mild reaction conditions. ${ }^{[6]}$ They employed BnO-cupreine 55, and were able to achieve a group of eleven synthetically useful 3-indolyl-3-hydroxy-2-oxindoles 54 in excellent yields (up to 99\%) and high enantioselectivitiy (up to $99 \%$ ee). It appeared that the electronic effects in isatins as well as in indoles had limited influence on the yield and enantioselectivity of the products. Based upon the observed results, the authors established a ternary complex transition state similar to the one in Figure 10 where the catalyst would play a dual role by simultaneous activation of both reactants, indole 52 and isatin 1 , by the quinuclidine moiety and the acidic 6'-OH group of the catalyst 55 (Figure 11).
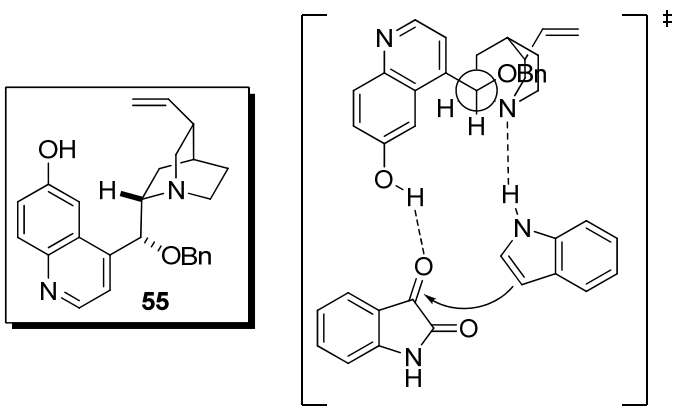

Figure 11. TS model for BnO-cupreine $\mathbf{5 5}$ catalyzed enantioselective FriedelCrafts reaction.

\section{Enantioselective Henry reaction}

The catalytic asymmetric nitroaldol reaction, also known as the Henry reaction, is an efficient method for the synthesis of chiral $\beta$-nitroalcohols, which are valuable building blocks in organic synthesis. ${ }^{[57]}$ To date, both chiral organocatalysts ${ }^{[58]}$ and chiral metallic complexes have been developed efficiently for this reaction. ${ }^{[59]}$ Although aldehydes have been successfully used as substrates in the asymmetric Henry reaction, the use of isatin derivatives has not been extensively explored as Henry acceptors for the enantioselective construction of quiral centers, ${ }^{[13,60]}$ due to their strong tendency to retro-nitroaldol reaction under basic conditions. ${ }^{[61]}$

Wang and co-workers reported in 2011 the first organocatalytic asymmetric Henry reaction of isatins in presence of natural cupreine (53) under mild reaction conditions (Scheme 13). ${ }^{[62]}$ As revealed from the experimental results, the process proved to be a general strategy for the synthesis of useful chiral 3-substituted-3-hydroxy-2-oxindoles $\mathbf{5 7}$ with significant structural variations. Remarkably, in all cases, the reactions proceeded very fast, with excellent yields ( $99 \%$ in all cases), without purification by chromatography, and with good to high enantioselectivities (74-93\% ee).

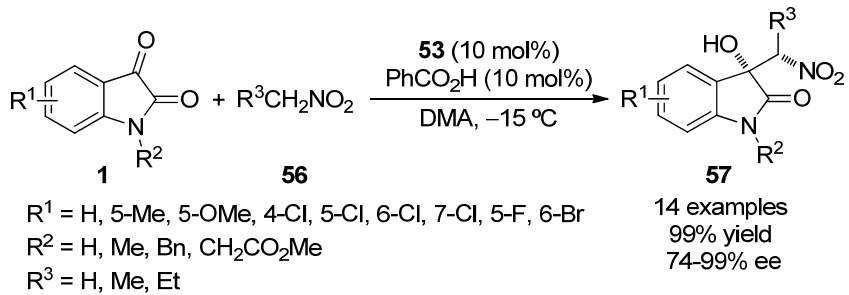

Scheme 13. Cupreine (53) catalyzed enantioselective Henry reaction.

As in previous proposed transition states both the 6 '-OH and 9-OH groups of $\mathbf{5 3}$ were essential for the stereocontrol of the reaction. Proposed transition state (TS) model supports the high enantioselectivity provided by cupreine (53) catalyst in this Henry reaction between isatin 1 and nitromethane acting in a dual faction (Figure 12). Bifunctional catalyst $\mathbf{5 3}$ activates nitromethane through the quinuclidine amine group and enables the activation of isatin through double-hydrogen-bonds with the 6'- and 9-OH groups to deliver product $\mathbf{5 7}$ with a high level of enantioselectivity and with the observed absolute (R)configuration.

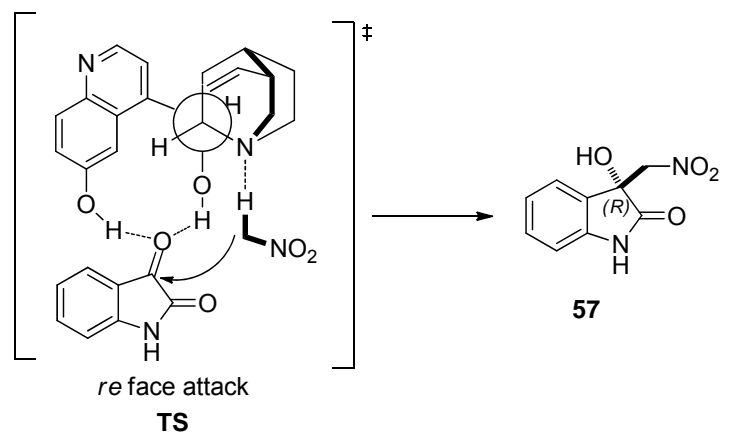

Figure 12. Proposed TS for cupreine $\mathbf{5 3}$ catalyzed Henry reaction. 
To illustrate the synthetic utility of this methodology, the first asymmetric total synthesis of (S)-(-)-spirobrassinin 60 , a natural product which displays various biological properties, was reached in four steps from $\mathbf{5 7}$ as shown in Scheme 14.

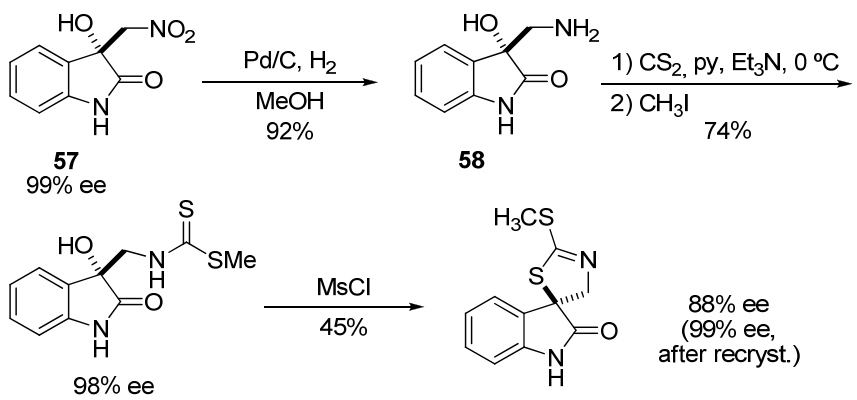

(+)-Dioxibrassinin (59)

(S)-(-)-Spirobrassinin (60)

Scheme 14. First asymmetric total synthesis of (S)-(-)-spirobrassinin (60).

Independently, a similar work was reported by Wang and coworkers. ${ }^{[63]}$ They described the asymmetric Henry reaction of isatins with nitromethane promoted by a series of bifunctional catalysts based on cinchona alkaloid scaffold, among those C93,5-( $\left(\mathrm{CF}_{3}\right)_{2}$-benzoylcupreine $\mathbf{6 1}$ with electron-withdrawing substituent was chosen as the most efficient and promising catalyst to deliver desired Henry adducts $\mathbf{5 7}$ with excellent yields (up to $97 \%$ ) and high enantioselectivities (up to $92 \%$ ee) (Figure 13). This catalytic strategy was further applied in the total synthesis of $(R)-(+)$-dioxibrassinin (59) and (S)-(-)-spirobrassinin (60).

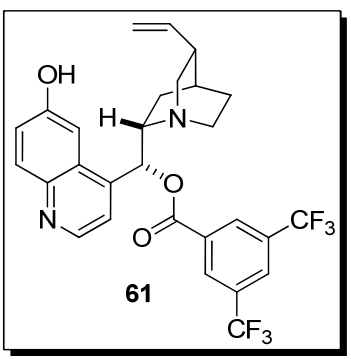

Henry adducts 57 up to $97 \%$ yield up to $92 \%$ ee
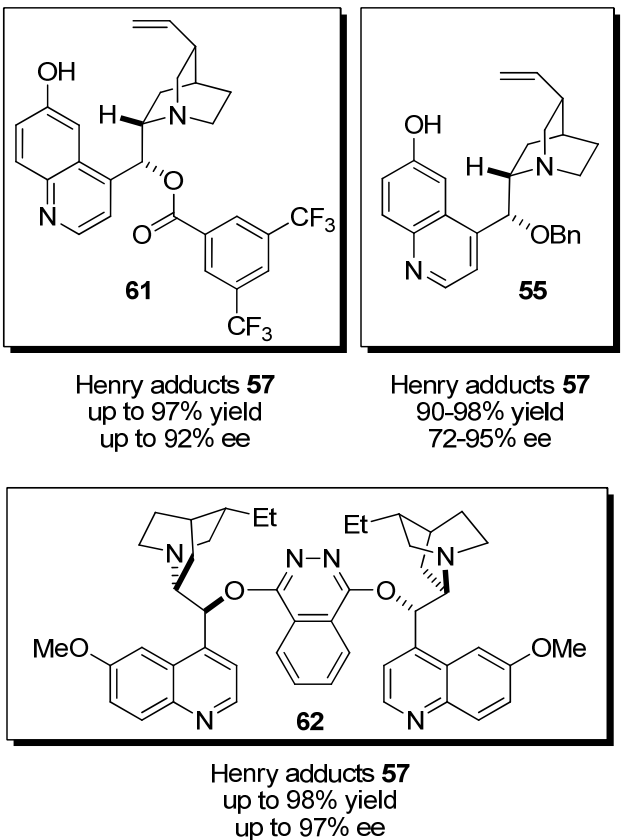

Figure 13. Catalysts 55, 61-62 used in the enantioselective Henry reaction of isatins 1 with nitroalkanes 56 .

The viability of an additional nitroaldol reaction between isatins and nitromethane was demonstrated by using BnOcupreine $\mathbf{5 5}$ as an acid-base bifunctional catalyst for providing final 3-hydroxy-3-(nitromethyl)indolin-2-ones $\mathbf{5 7}$ with good yields
(90-98\%) and good to high enantioselectivities (72-95\% ee) (Figure 13) ${ }^{[64]}$ Biscinchona alkaloid 62 was also employed as active catalyst in a simple protocol to promote the same reaction. Final Henry adducts $\mathbf{5 7}$ were obtained with high yields (up to $98 \%$ ) and high enantioselectivities (up to $97 \%$ ee) (Figure 13). ${ }^{[65]}$

\section{Enantioselective Strecker reaction}

Cyanation of imines, known as the Strecker reaction is a powerful strategy to obtain $\alpha$-amino nitriles ${ }^{[66]}$ Even today, after more than 160 years, this reaction attracts much attention from chemists, mainly because this reaction represents a direct and simple approach for the construction of $\alpha$-amino acids. ${ }^{[67]}$ Since the first report of a catalytic enantioselective Strecker reaction in $1996,{ }^{[68]}$ the enantioselective version of this reaction has been a very interesting topic in organic chemistry and great progresses have been accomplished in both fields, metal catalysis ${ }^{[69]}$ and organocatalysis. ${ }^{[70]}$ However, catalytic enantioselective Strecker reactions using ketimines as substrates are very limited and only one example has been reported regarding isatin. ${ }^{[71]}$

Zhou and co-workers reported the first enantioselective Strecker reaction of isatins derived ketimines $\mathbf{6 3}$ with trimethylsilyl cyanide (TMSCN), promoted successfully by bifunctional cinchona alkaloid-based phosphinamide catalyst 64 (Scheme 15) ${ }^{[72]}$ Under the best reaction conditions, a number of ketimines 63 were examined to give $\alpha$-amino nitriles 65 with moderate to good yields (up to $72 \%$ ) and enantioselectivities (up to $74 \%$ ee).

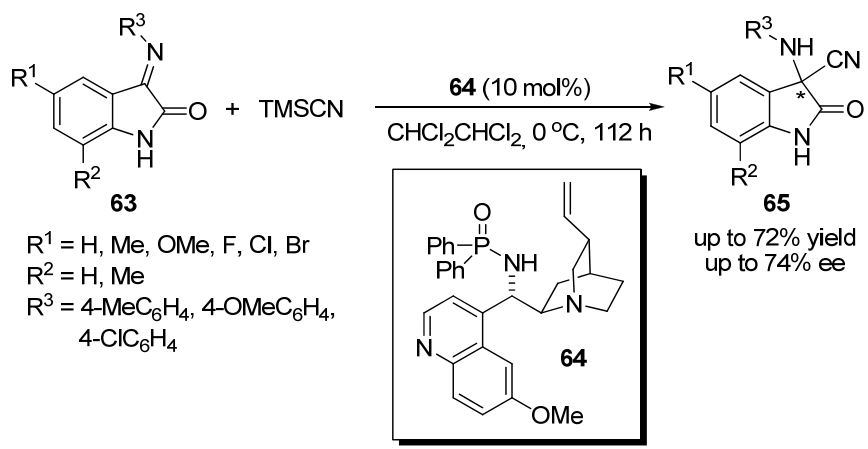

Scheme 15. First enantioselective Strecker reaction of ketimines 63 with TMSCN catalyzed by cinchona alkaloid-based phosphinamide 64 .

\section{Enantioselective Pictet-Spengler reaction}

The Pictet-Spengler (PS) reaction is an acid catalyzed cyclization between a tryptamine derivative and an aldehyde. ${ }^{[73]}$ This condensation has been of pivotal importance in the synthesis of numerous tetrahydroisoquinolines and tetrahydro- $\beta$-carbolines that are core structure elements in natural and synthetic organic compounds possessing a wide diversity of important biological activities. $^{[74]}$

Moreover, in recent years, there has been a considerable growth of interest in the synthesis of spirooxindole derivatives because of the wide-ranging biological activity associated with them, such as antibacterial, antifungal, antiinflammatory, and antipyretic activities (Figure 14). ${ }^{[12 b, 75]}$ 


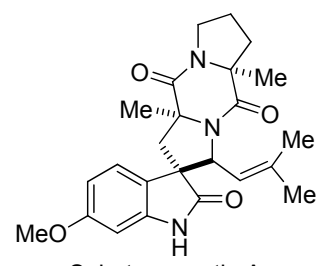

Spirotryprosatin A<smiles>CC(=O)C1=COC[C@@H]2[C@@H]1C[C@@H]1[C@H]2C[C@]12C(=O)N(C)c1ccccc12</smiles>

Alstonisine

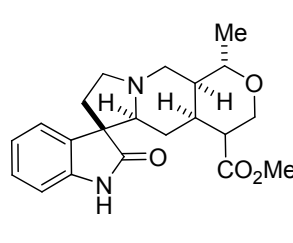

Peteropodine<smiles>CC1Cc2c([nH]c3cc(Cl)c(F)cc23)[C@]2(C1)NC(=O)Nc1ccc(Cl)cc12</smiles>

NITD609<smiles>O=C1CC2CCNc3cc(O)cc(c32)N1</smiles>

Isoelacomine

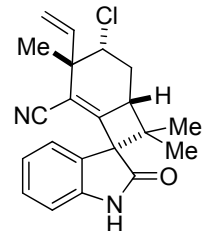

Welwitindolinone A
Figure 14. Examples of biologically active spirooxindoles.

In this context, the first access to this class of compounds in an enantioselective manner through a Pictet-Spengler strategy was acomplished by Bernardi and co-workers with a chiral Brønsted acid catalyzed reaction between isatins 1 and tryptamines 66 (Scheme 16) ${ }^{[76]}$ The viability of the method was explored with several (S)-BINOL derived phosphoric acids with different substituents at the 3 and 3' positions to afford tetrahydro$\beta$-carbolines 68. The results showed that 3,3 '-substituents on binaphthyl system strongly influenced the enantioinduction of the process. Therefore, the most competent catalyst was the triisopropylphenyl-substituted phosphoric acid 67 giving easy access to optically active spiroindolinones 68 with excellent enantioselectivities (up to $95 \%$ ee) and high yields (68-97\%).

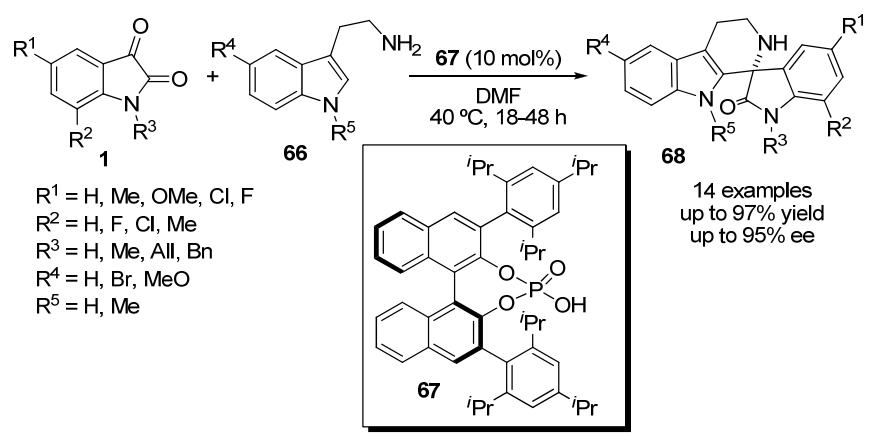

Scheme 16. Enantioselective catalyzed PS reaction by triisopropylphenylsubstituted (S)-BINOL phosphoric acid 67.

In a similar study, Franz and co-workers proposed that the phosphoric acid $\left(\mathrm{HA}^{*}\right)$ promoted the reaction through an iminium ion intermediate that is capable of forming an iminium-phosphate ion pair $\mathbf{6 9}$ after the condensation between the tryptamine $\mathbf{6 6}$ and the isatin 1 (Scheme 17). ${ }^{[7]}$ Intramolecular nucleophilic attack of the indole from its 2-position would lead to spirocyclization and formation of the new chiral carbon center. Finally, the resulting indolenium ion $\mathbf{7 0}$ undergoes an elimination to reestablish the aromaticity of the system, generating spiroindolone 68 and regenerating the catalyst $\left(\mathrm{HA}^{*}\right)$.

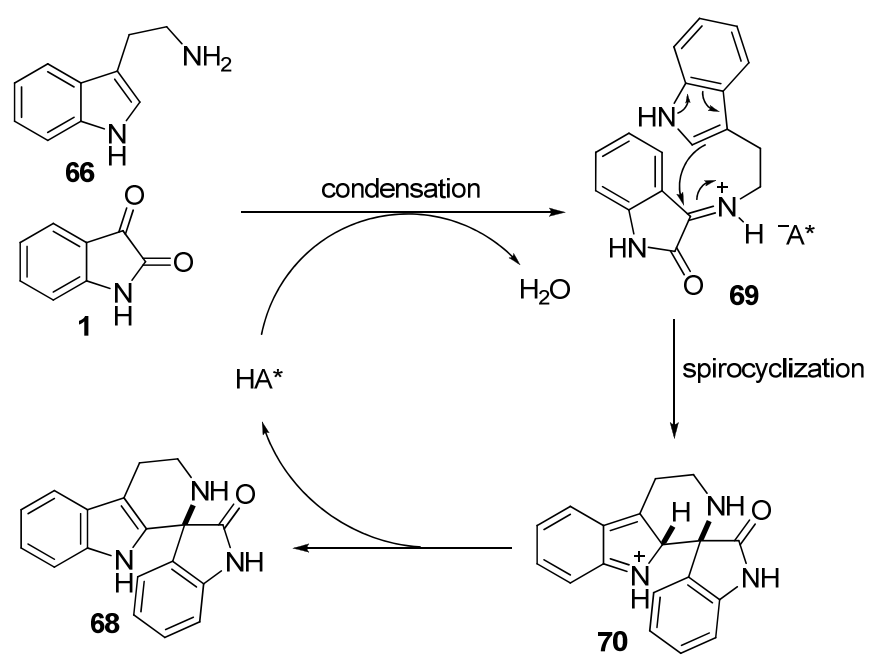

Scheme 17. Plausible spirocyclization mechanism in the presence of chiral phosphoric acid $\left(H A^{*}\right)$.

\section{Enantioselective hydrophosphonylation reaction}

Chiral $\alpha$-hydroxyphosphonates have recently received significant attention due to their biological and physical properties, as well as their utility as synthetic intermediates. ${ }^{[78]}$ The reaction of aldehydes or ketones with dialkyl or trialkylphosphites in the presence of acidic or basic catalysts is the most frequently used approach for the synthesis of this class of compounds. ${ }^{\text {[9] }}$ However, and in spite of the interest of the resulting backbones, asymmetric phospho-aldol reaction using isatin have not drawn much attention. ${ }^{[80]}$

Only one successful enantioselective example of phosphoaldol reaction has been recently reported by $\mathrm{Xu}$, Wang and coworkers (Scheme 18). ${ }^{[81]}$ Between all catalysts examined in this reaction, commercially available quinine (72) led to promising results being the catalyst of choice for further investigations and to explore the scope of this pioneering process. Thus, under the optimal conditions the enantioselective hydrophosphonylation reaction of diphenylphosphite (71) with $\mathrm{N}$-alkylated isatin derivatives 1 was carried out affording chiral $\alpha$ hydroxyphosphonates 73 in good to excellent yields (60-90\%) and moderate to good enantioselectivities (25-67\% ee).

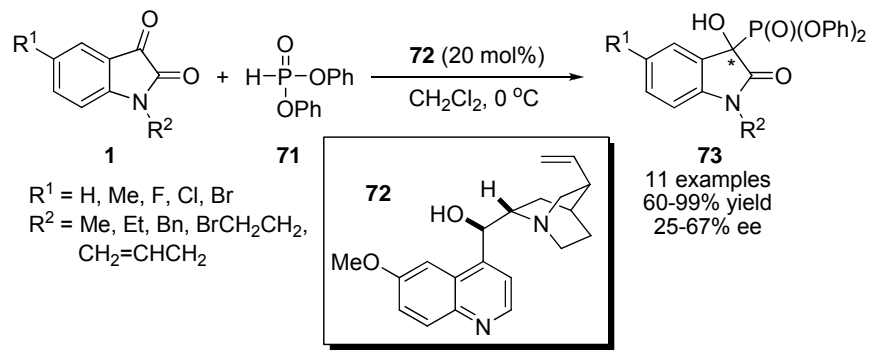

Scheme 18. Quinine (72) catalyzed enantioselective hydrophosphonylation reaction.

According to the experimental results, a possible transition state involving a ternary complex between $\mathrm{N}$-methylisatin $\mathbf{1}$, diphenylphosphite (71) and the catalyst 72 was suggested, as represented in Figure 15. As reflected in this model, the carbonyl group of isatin would be activated by the $\mathrm{OH}$ group of quinine (72) 
through $\mathrm{H}$-bond interaction, and at the same time the phosphite would be activated by the quinuclidine amine group. The dual role played by the catalyst in a synergic effect would control the attack of the phosphite (71) over the isatin 1, releasing the final product 73.

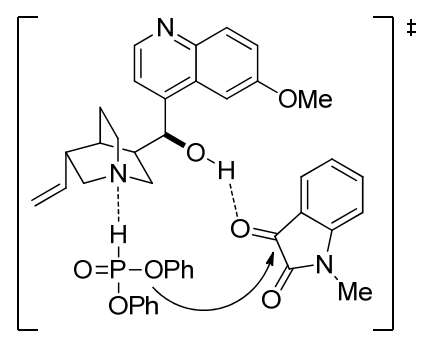

Figure 15. Proposed TS for the quinine-catalyzed phospho-aldol reaction.

\section{Asymmetric metal catalysis}

\section{Metal catalyzed enantioselective Friedel-Crafts reaction}

In 2009, for the first time, Franz and co-workers employed chiral scandium(III) and indium(III) complexes in the development of a direct method for enantioselective and regioselective addition of indole and other nucleophiles to isatins 1 (Scheme 19). ${ }^{[82]}$ The results demonstrated that between the chiral ligands explored the use of the inda-pybox ligand led to high enantioselectivity with several metals. Either scandium(III)-inda-pybox $\mathbf{7 4}$ or indium(III)inda-pybox 76 catalysts were found to afford products 75 with excellent yields and enantiomeric excesses for a variety of substituted isatin electrophiles and various electron-rich nucleophiles. However, better results were reached in general with scandium(III) complex $\mathbf{7 4}$ compared with indium(III) complex.

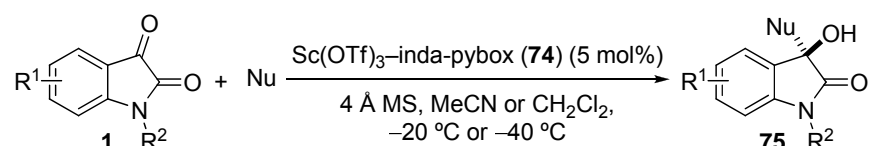

$$
\text { (n) }
$$

Scheme 19. Sc-catalyzed enantioselective Friedel-Crafts reaction of isatins 1 with a variety of nucleophiles.

Significantly, a recent study by the same group has been focused on the application of indium(III)-inda-pybox complex $\mathbf{7 6}$ in the first catalytic addition of pyrrole $\mathbf{7 7}$ to isatin derivatives 1 with excellent enantioselectivities (up to $99 \%$ ee) and yields (up to $98 \%$ ) (Scheme 20$).{ }^{[83]}$ It is worth noting that ee values were sensitive to metal and solvent effects, as well as the electronic and steric substitution pattern of both coupling partners.

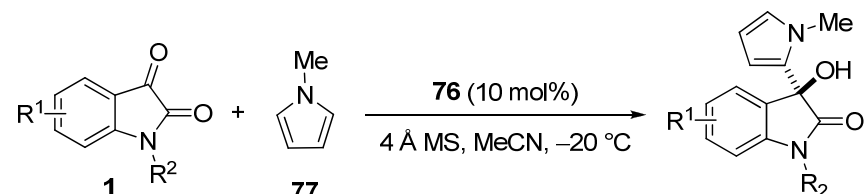

$\mathrm{R}^{1}=\mathrm{H}, 4-\mathrm{Cl}, 5-\mathrm{Br}, 5-\mathrm{Cl}$, $5-\mathrm{F}, 5-\mathrm{MeO}$

$\mathrm{R}^{2}=\mathrm{H}, \mathrm{Me}, \mathrm{C}_{3} \mathrm{H}_{3}, \mathrm{PMB}$

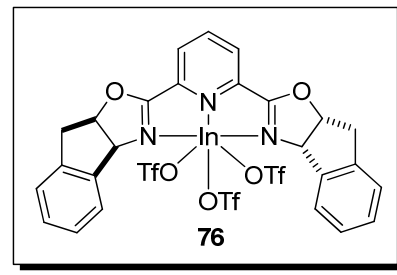

up to $98 \%$ yield up to $99 \%$ ee
Scheme 20. Enantioselective addition of pyrrole 77 in the presence of chiral indium(III)-inda-pybox complex 76.

\section{Vinylogous Mannich reaction}

Early research into vinylogous Mannich reaction ${ }^{[84]}$ showed that it has acquired increasing attention as a powerful tool for $\mathrm{C}-\mathrm{C}$ bond formation for synthesis of highly functionalized $\alpha$-amino compounds. Although the first asymmetric vinylogous Mannich reaction of trimethylsilyloxyfuran (TMSOF) to $\alpha$-ketimine esters was developed in 2009 with high enantioselectivity, ${ }^{[85]}$ only recently Deng and co-workers has reported a diastereoselective catalytic variant of this reaction using isatin-based ketimine 63 and TMSOF (79) by employing AgOAc to promote the reaction pathway for the synthesis of 3 -aminooxindoles $\mathbf{8 0}$ that is a frequent core unit in natural products (Scheme 21). ${ }^{[86]}$

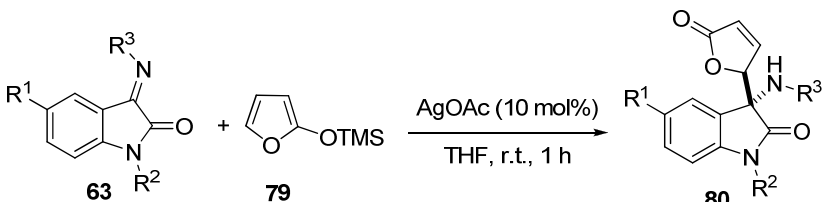

$80 \mathrm{R}^{2}$<smiles>[R]CN=C1C(=O)N([R])c2ccc([R1])cc21</smiles>

Scheme 21. AgOAc-catalyzed vinylogous Mannich reaction of 63 and 79.

The ability of AgOAc to promote this reaction compared to other metal salts, such as copper, zinc or nickel, was higher leading to the desired products 80 with excellent yields (94-99\%) 
and complete anti-diastereoselectivity (>99:1) under very mild conditions. The authors invoked a transition state based on the well-known bifunctional capacity of this specie to explain the relative configuration observed in the final products $\mathbf{8 0}$ (Scheme 21). In this plausible transition state, $A g(I)$ is coordinated as Lewis acid to 2 equivalents of substrate, and acts also as base after coordinating to TMSOF (79) and releasing $\mathrm{OAc}^{-}$, which is real base to capture the TMS group and consequently promoting the attack of TMSOF (79) over the isatin 1.

\section{Metal catalyzed enantioselective alkenylation, arylation and allylation}

\section{Metal catalyzed addition of arylboronic acids}

Most of the reported routes for catalytic enantioselective addition of organometallic nucleophiles to $\alpha$-dicarbonyl substrates have been limited to alkynyl ${ }^{[87]}$ or alkyl zinc reagents. ${ }^{[88]}$ However, in 2006 Vries, Feringa, Minnaard and co-workers provided a general method using the combination of rhodium-catalyst and a variety of arylboronic acids $\mathbf{8 1}$ to synthesize 3-aryl-3-hydroxyoxindoles 82, in pronounced high yields (up to $99 \%$ ) (Scheme 22). ${ }^{[89]}$ Only an asymmetric example have been reported, obtaining moderate enantioselectivity with chiral ligand L1 $(55 \%$ ee, $94 \%$ ee after recrystallization)

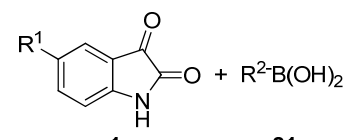

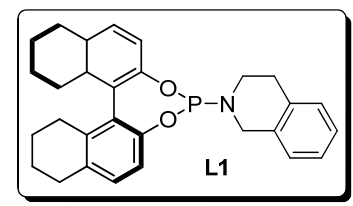

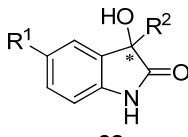

82 13 examples L1 (9 mol\%) $\quad 99 \%$ yield, $55 \%$ ee dioxane, $40^{\circ} \mathrm{C}, 4 \mathrm{~h} \longrightarrow(59 \%$ yield, $94 \%$ ee after recryst.)
$\left[\left(\mathrm{C}_{2} \mathrm{H}_{4}\right)_{2} \mathrm{Rh}(\right.$ acac $\left.)\right](3 \mathrm{~mol} \%) \quad$ for $\mathrm{R}^{1}=\mathrm{H}, \mathrm{R}^{2}=\mathrm{Ph}$

Scheme 22. Rh-catalyzed enantioselective addition of aryl- and alkenylboronic acids 81 to isatins 1 .

In addition, in this protocol electron-donating groups on the isatin substrate decreased the reactivity (yield 62\%), while electron-donating substituents on the boronic acid improved the reactivity (yield 99\%). Authors proposed a plausible mechanism, where alkoxy species 85 resulting from the arylation of the carbonyl function, is believed to act as a nucleophile in the transmetalation step to regenerate the catalytic active intermediate 83 (Scheme 23). ${ }^{[90]}$

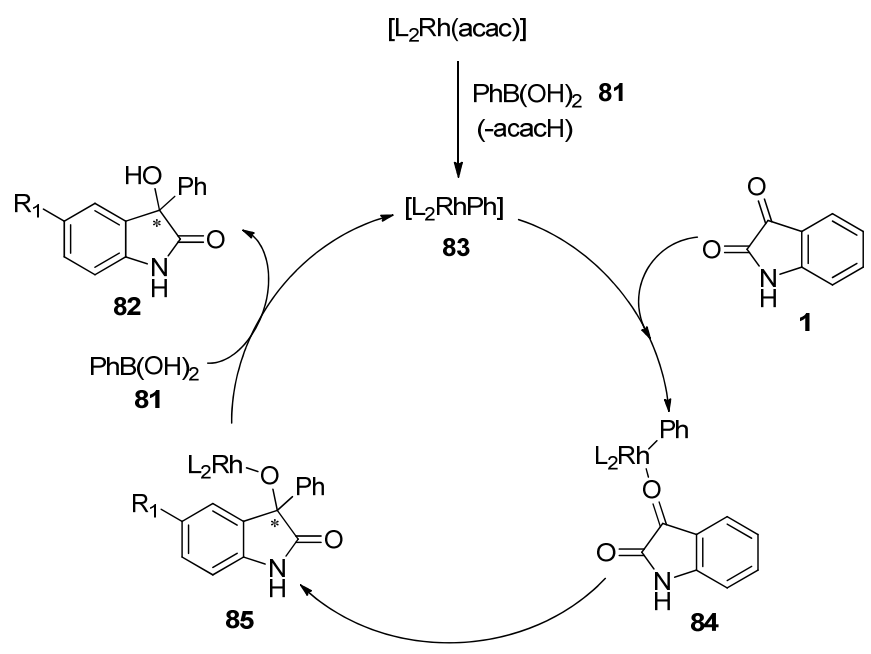

Scheme 23. Proposed mechanism of the Rh-catalyzed 1,2-addition of arylboronic acids $\mathbf{8 1}$ to isatins $\mathbf{1}$.

Independently, Hayashi and co-workers described a more general methodology of this reaction using $\mathrm{Rh} /(R)-\mathrm{MeO}-\mathrm{mop}($ L2) complex catalyst for the addition of arylboronic acids $\mathbf{8 1}$ to isatins 1 under mild conditions, achieving high enantioselectivity (up to $93 \%$ ee) (Scheme 24). ${ }^{[91]}$

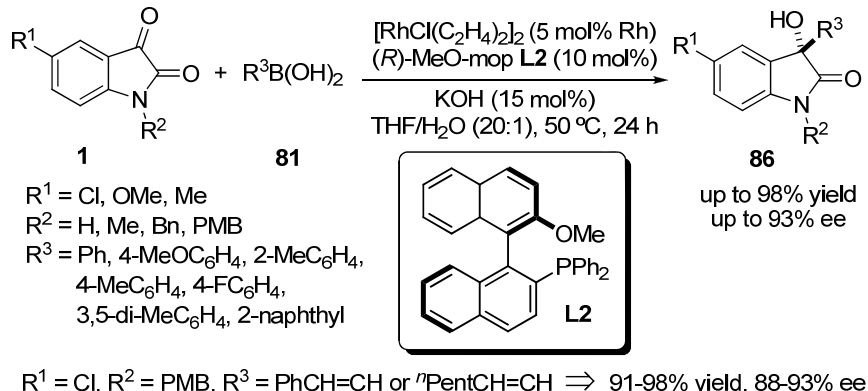

Scheme 24. Rh-catalyzed chiral addition of arylboronic acids 81 to isatins 1

Between the diverse chiral phosphine ligands tested, $(R)$ MeO-mop (L2), an axially chiral mono-phosphine ligand, gave remarkable higher yields and significantly improved the enantioselectivity (92\% yield, $90 \%$ ee) for various arylboronic acids $\mathbf{8 1}$ and different $\mathrm{N}$-protected isatin derivatives $\mathbf{1}$. Moreover, the authors were able to extend their protocol to alkenylboronic acids for the synthesis of tertiary allylic alcohol derivatives in excellent yield and with high ee values (91-98\% yield, $88-93 \%$ ee).

In 2009, an example of chiral Pd-complex was also disclosed to catalyze the asymmetric addition of arylboronic acids 81 to $\mathrm{N}$ benzylisatin 1 with moderate yields and enantioselectivities (Scheme 25) ${ }^{[92,93]}$ The ability of various Pd-salts with different new synthesized chiral biaryl-phosphino-sulfinyl imine ligands for promoting the arylation reaction was explored. The most promising results were achieved using combination of $\mathrm{Pd}(\mathrm{OAc})_{2} / \mathrm{L3}$ and $\mathrm{BF}_{3} \cdot \mathrm{Et}_{2} \mathrm{O}$ as a Lewis acid to improve the reactivity of isatin, affording tertiary alcohols $\mathbf{8 7}$ with moderate enantioselectivities. 


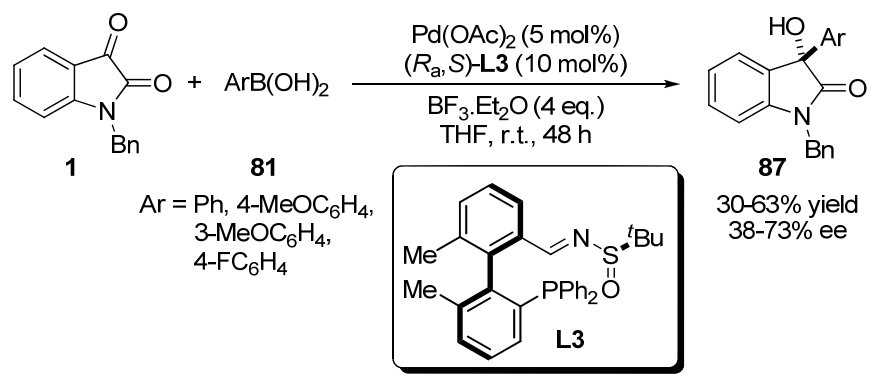

Scheme 25. Pd-catalyzed asymmetric addition of arylboronic acids $\mathbf{8 1}$ to isatins 1

On the basis of the results, it was observed that the absolute configuration of final product was controlled by the axial chirality of the ligands rather than the sulfinyl group chirality.

\section{Metal catalyzed addition of arylsilanes and alkenylsilanes}

Although many methods for the synthesis of optically active 3aryl-3-hydroxy-2-oxindoles have been developed, none of them has allowed the synthesis of a highly active non-peptidic growth hormone secretagogue SM-130686 (90) because of a bulky group on C4 position (Scheme 27). In 2009, the discovery of a highly efficient enantioselective synthesis of 3-aryl-3-hydroxy-2oxindoles 89 was published based on Cu-catalyzed alkenyl- or arylation of isatin 1 by silanes reagents 88 (Scheme 26). ${ }^{[94,95]}$ This reaction was applied to isatin substrates 1 and a variety of aryland alkenylsilanes $\mathbf{8 8}$ in the presence of Cu-catalyst and optimum chiral ligand L4 for generating reactive aryl- or alkenyl-copper species by transmetalation from the stoichiometric silicon-based reagents. Catalytic fluoride additives (such as TBAT or $\mathrm{PhBF}_{3} \mathrm{~K}$ ) improved the reactivity without affecting the enantioselectivity. The DMTr (dimethoxytrityl) protecting group of 89 was further removed easily with $10 \%$ TFA in $\mathrm{CH}_{2} \mathrm{Cl}_{2}$ in the presence of $p$ anisole in high yield without any racemization.

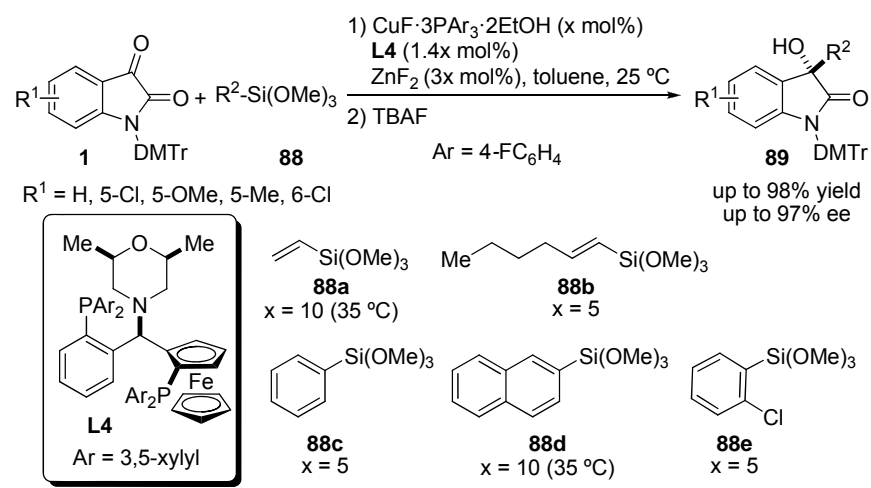

Scheme 26. Cu-catalyzed enantioselective alkenylation and arylation of isatins 1.

The interest of this method resides in its application as a key step for the first catalytic synthesis of highly optically active SM130686 (90). To overcome the unsatisfactory efficiency of the previously shown intermolecular arylation addition in the synthesis of $\mathbf{9 0}$, the same authors developed a more efficient catalytic enantioselective intramolecular arylation of $\alpha$-keto amides 91 as an alternative strategy (Scheme 27).

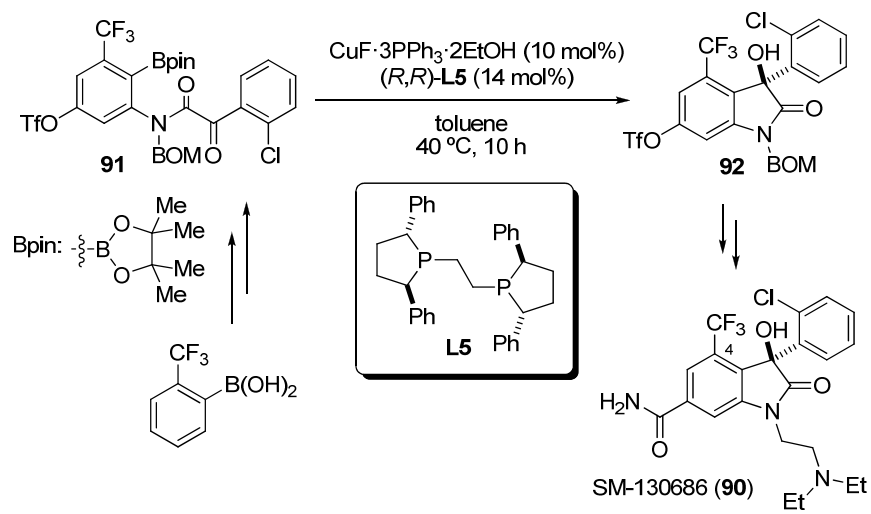

Scheme 27. Cu-catalyzed enantioselective intramolecular arylation in the synthesis of SM-130686 (90).

\section{Enantioselective iridium-catalyzed allylation, crotylation, and reverse prenylation of isatins}

Krische and co-workers have reported the first enantioselective allylation, crotylation, and reverse prenylation of isatins, with good yields and high enantioselectivities (Scheme 28). ${ }^{[96]}$ In contrast to other classical allylation systems based on the use of stoichiometric quantities of allyl-metal reagents, ${ }^{[97]}$ this method by isopropanol-mediated transfer hydrogenation, uses allyl acetate, $\alpha$-methyl allyl acetate, and 1,1-dimethylallene as precursors to transient allyl-, crotyl-, and prenyl-metal intermediates, respectively. The use of cyclometalated $C, O$-benzoate generated in situ from $\{\mathrm{Ir}(\operatorname{cod}) \mathrm{Cl}\}_{2}$, CTH- $(R)-\mathrm{P}-\mathrm{Phos}(\mathrm{CTH}-(R)-\mathrm{P}-\mathrm{Phos}=(R)-$ (+)-2,2',6,6'-tetramethoxy-4,4'-bis(diphenylphosphino)-3,3'bipyridine) and 3-nitrobenzoic acid derivatives, gave the best results.

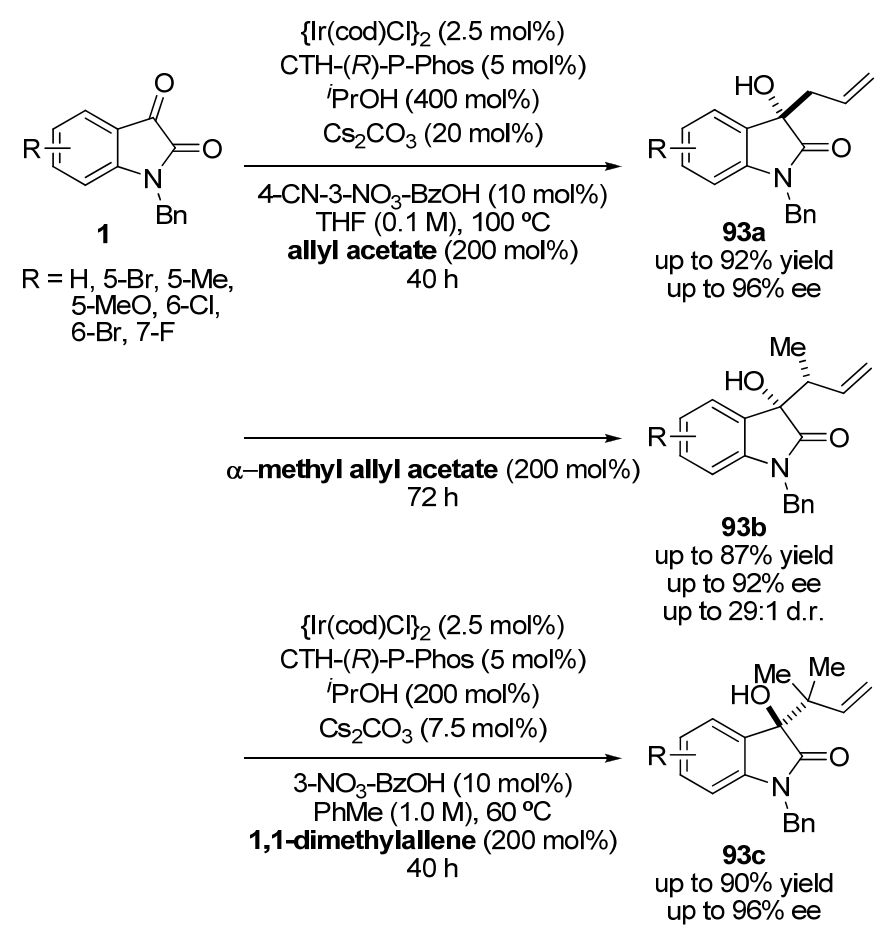

Scheme 28. Ir-catalyzed enantioselective allylation, crotylation and reverse prenylation of $\mathrm{N}$-benzyl isatins 1 . 
Opposite absolute configuration is observed in the case of carbonyl reverse prenylations employing 1,1-dimethylallene respect to the corresponding allylations and crotylations. The authors proposed an analogous mechanism for carbonyl reverse prenylation (Scheme 29a), ${ }^{[98]}$ through a chairlike transition structure and an $(E)-\sigma$-crotyl iridium intermediate. Thus, in order to explain the different configuration is possible to propose that isatin crotylation occurs by way of the transition structure $\mathbf{A}$, whereas isatin reverse prenylation occurs by way of the transition structure B (Scheme 29b), since nonbonded interactions of axial methyl group with the electron-deficient rim of the arene is presumably less destabilizing than nonbonded intermediate with the amide $\pi$ bond of isatin.

a)

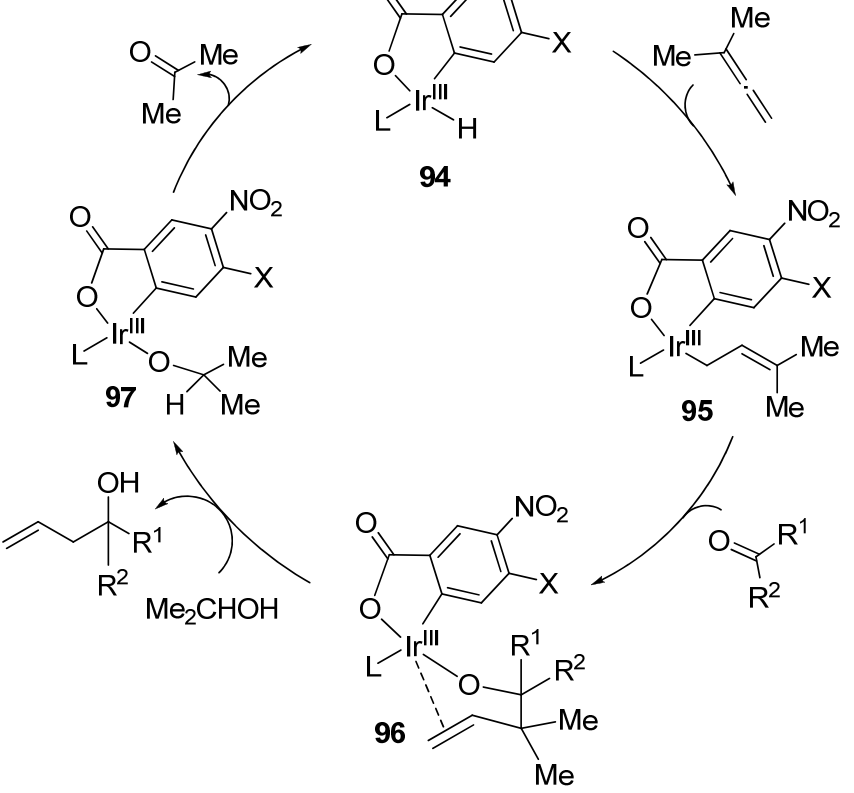

b)

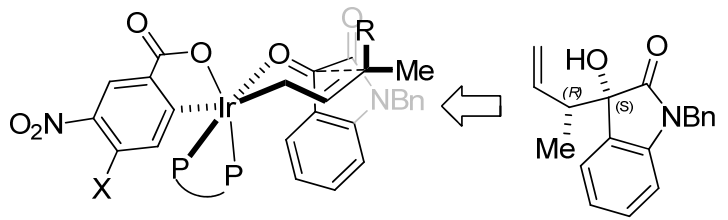

A (favored for $\mathrm{R}=\mathrm{H}$ )

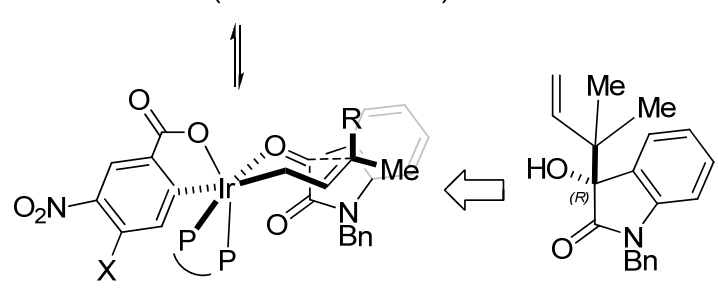

B (favored for $\mathrm{R}=\mathrm{Me}$ )

Scheme 29. Mechanism hypothesis.

\section{Hosomi-Sakurai allylation of isatins}

The Hosomi-Sakurai reaction involves the Lewis acid-promoted allylation of various electrophiles with allylsilane. ${ }^{[9]}$ A short enantioselective version of this strategy was successfully applied by Zhou and co-workers for the asymmetric allylation of isatins, using $1 \mathrm{~mol} \%$ of chiral mercury catalyst (S)-
BINAP/Hg(ClO $)_{2} \cdot 3 \mathrm{H}_{2} \mathrm{O}$ in THF to yield the (S)-enantiomer of product 99 with excellent yield (up to 96\%) and moderate enantioselectivities (up to $63 \%$ ee). This is the first example of catalytic asymmetric allylation of ketones using less reactive allyltrimethylsilane (98) (Scheme 30$).{ }^{[100,101]}$
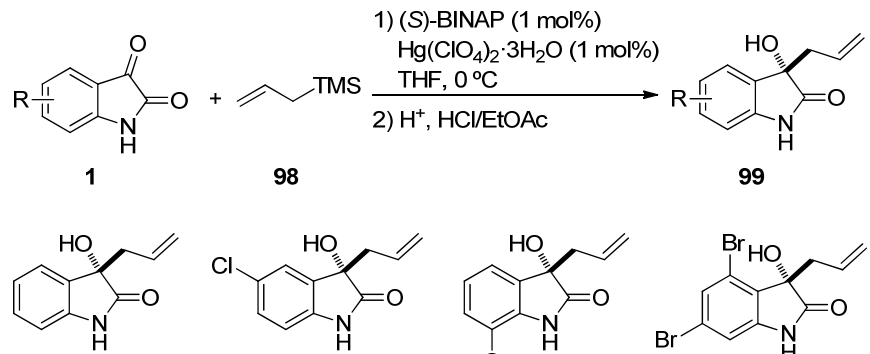

$93 \%$ yield $56 \%$ ee

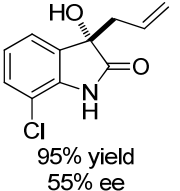<smiles>C=CCC1(O)C(=O)Nc2cc(Br)cc(Br)c21</smiles>

Scheme 30. Hg-catalyzed enantioselective allylation of isatins 1.

\section{Catalytic asymmetric [3+2] annulation of allylsilanes with isatins}

Catalytic asymmetric [3+2] annulation of allylsilanes with isatins has recently emerged by Franz and co-workers as a new route to afford silyl-substituted spirooxindoles 101 with excellent enantioselectivities (up to $99 \%$ ee), an important class of compounds with biological activities (Scheme 31). ${ }^{[102,103]}$

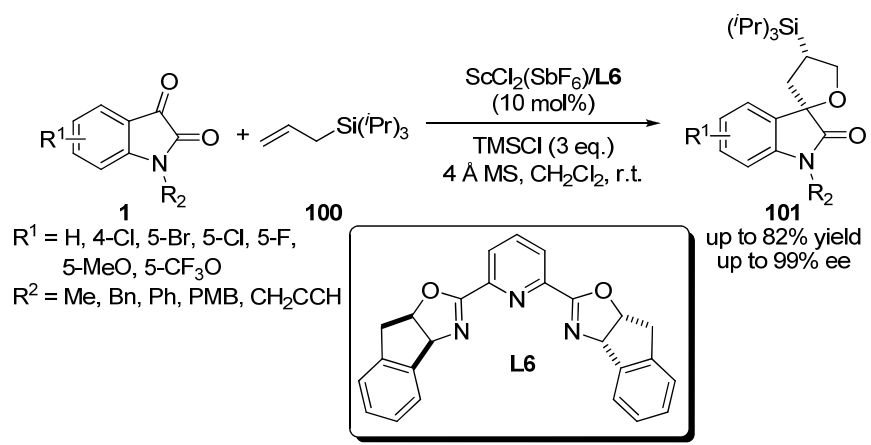

Scheme 31. Sc-catalyzed [3+2] annulation of allylsilane 100 .

To optimize the reaction, diverse chiral Sc-complexes and various additives such as $\mathrm{AgSbF}_{6}$ and trimethylsilyl chloride (TMSCl) to enhance the reactivity of the catalysts were explored. Consequently, TMSCl as activator played a key role for the appropriate choice of the best catalyst system, and improving both rate enhancement and product ratio (between the competing annulation and allylation reactions). In all cases the desired product $\mathbf{1 0 1}$ was obtained in good yield (up to $82 \%$ ) and excellent enantioselectivity (up to $99 \%$ ee). Although in this protocol both allylation and [3+2] annulation pathways can take place, several allylsilanes 100 with various steric and electronic properties were examined to identify an allylsilane that favored mainly the annulation pathway. In general, bulky silyl groups predominantly led to annulation pathways, and silyl reagents with aromatic moieties afforded allylation reaction, but with a "removable" aromatic moiety the silyl group of the resulting adducts can be easily converted into a hydroxy group under mild oxidation conditions (Scheme 32). 


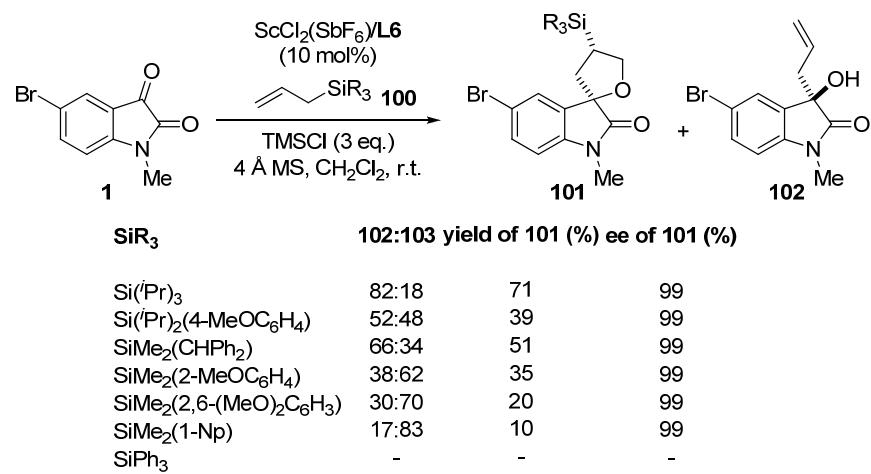

Scheme 32. Sc-catalyzed [3+2] annulation-allylation ratios (101:102) for allylsilanes $\mathbf{1 0 0}$.

The authors demonstrated the utility of this protocol, synthetizing hydroxy-spirooxindoles $\mathbf{1 0 3}$ from easily oxidizable benzhydryl silyl group with TBAF and hydrogen peroxide. The reaction proceeds with high yields and retention of configuration (Scheme 33).<smiles>[R]N1C(=O)C(=O)c2c[R1]ccc21</smiles>

1) $\mathrm{ScCl}_{2}\left(\mathrm{SbF}_{6}\right) / \mathrm{L}_{6}(10 \mathrm{~mol} \%)$

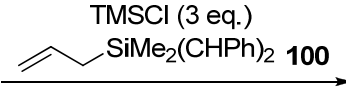

2) TBAF, THF, $0^{\circ} \mathrm{C}, \mathrm{H}_{2} \mathrm{O}_{2}$ $\mathrm{KHCO}_{3}, \mathrm{MeOH}$, r.t.<smiles>[R]N1C(=O)C2(C[C@H](O)CO2)c2cc[R1]cc21</smiles>

103

4 examples up to $93 \%$ yield up to $99 \%$ ee
Scheme 33. Enantioselective allylsilane annulation and C-Si oxidation.

After this pioneering example, the same group designed a catalytic enantioselective Hosomi-Sakurai allylation and crotylation of isatins with various substituted allylic silanes 104 using a $\mathrm{Sc}$ (III)-inda-pybox (L6) complex with TMSCl as activator and $\mathrm{NaSbF}_{6}$ as additive to achieve 3-allyl-3-hydroxy-2-oxindoles 105 with high yields (up to $99 \%$ ) and excellent enantioselectivities (up to $99 \%$ ee) (Scheme 34 ). ${ }^{[104]}$

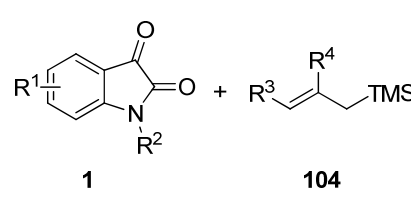

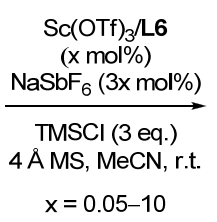

$\mathrm{x}=0.05-10$

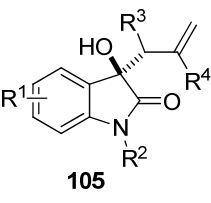

19 examples up to $99 \%$ yield up to $99 \%$ ee
Scheme 34. Sc-catalyzed enantioselective Hosomi-Sakurai allylation of isatins 1.

The peculiarity of this method is the possibility of carrying out the reaction using a very low catalyst loading $(0.05 \mathrm{~mol} \%)$ at room temperature, which makes it a useful protocol for synthetic intermediates and industrial applications. In fact, the scalability of this allylation reaction at low catalyst loading $(0.1 \mathrm{~mol} \%)$ was tested in a gram-scale reaction obtaining the same good results.
The first metal-catalyzed diastereoselective total synthesis of convolutamydines B (23) and E (22) have been developed by Kobayashi and co-workers using vinylogous Mukaiyama aldol reaction in the presence of $\mathrm{TiCl}_{4}$ in $\mathrm{CH}_{2} \mathrm{Cl}_{2}$, at $-78{ }^{\circ} \mathrm{C}$ (Scheme 35). ${ }^{[105]}$

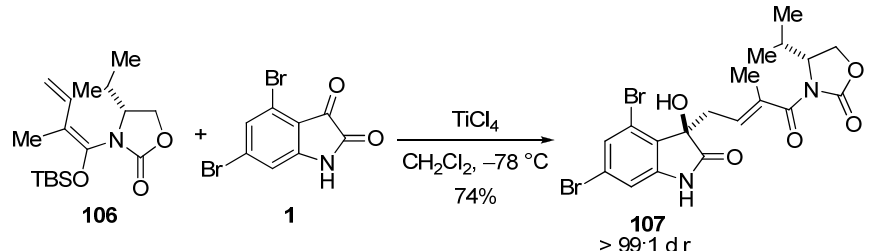

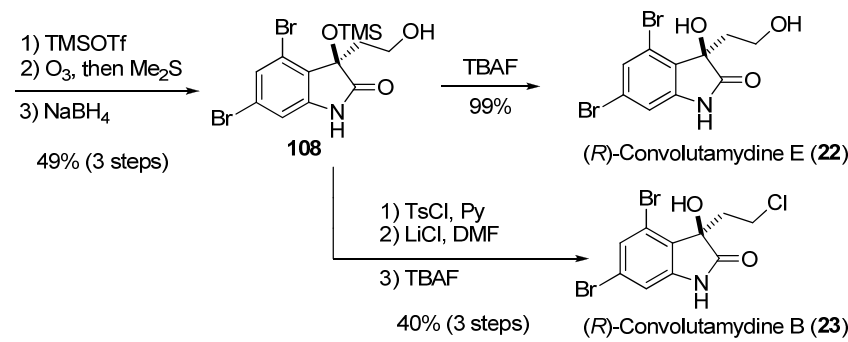

Scheme 35. Diastereoselective total synthesis of $(R)$-convolutamydines B (23) and $E(22)$.

They examined different reaction conditions with different starting materials (Figure 16) for aldol reaction, and finally the vinylogous Mukaiyama aldol reaction by using compound ent-106 showed the best yield (69\%) and stereoselectivity (60:1).<smiles>C=C(C)/C(C)=C(\OC(C)(C)C)N1C(=O)CCC1C(C)C</smiles>

ent-106

$\mathrm{TiCl}_{4}$ $69 \%(60: 1)$<smiles>C=C/C=C(\O[As])N1C(=O)OCC1C(C)C</smiles>

$32 \%(1.7: 1)$<smiles>CC(=O)N1C(=O)OCC1C(C)C</smiles>

110

${ }^{i} \mathrm{Pr}_{2} \mathrm{NEt}, \mathrm{TiCl}_{4}$ $45 \%(1.2: 1)$<smiles>C=C(OC(C)(C)C)N1C(=O)OCC1C(C)C</smiles>

$\mathrm{TiCl}_{4}$ $38 \%(2.8: 1)$
Figure 16. Typical nucleophiles for aldol reaction.

This procedure afforded 107 in good yield (74\%) with excellent diastereoselectivity (>99:1) and reproducibility. $(R)$ convolutamydine $E(22)$ and $B(23)$ were obtained from the product of this reaction by simple transformations (Scheme 35 ).

\section{Asymmetric addition of alkyl enol ethers to isatin via ene reaction}

The asymmetric carbonyl-ene reaction is one of the simplest methods for $\mathrm{C}-\mathrm{C}$ bond forming reactions to synthesize a stereogenic carbon atom. ${ }^{[06]}$ However, the use of alkyl enol ethers as the ene component has been scarcely explored ${ }^{[107]}$ because of the instability of these reagents in the presence of a Lewis acid and the probable competitive Mukaiyama aldol reaction versus ene pathway.

Very recently, Feng and co-workers have reported the first catalytic enantioselective hetero-ene reaction of alkyl enol ethers 112 with three kinds of 1,2-dicarbonyl compounds (including isatins, $\alpha$-ketoesters, and glyoxal derivatives) using the chiral 
$N, N^{\prime}$-dioxide L7 complex of $\mathrm{Mg}(\mathrm{OTf})_{2}$ under mild reaction conditions (Scheme 36). ${ }^{[08]}$ It was confirmed by the results that electron-withdrawing substituents on isatin led to higher reactivity and enantioselectivity even with a catalyst loading of $1-5 \mathrm{~mol} \%$ without producing the corresponding Mukaiyama aldol products 114. It is worth noting that $(R)$-convolutamydine $\mathrm{A}(\mathbf{5})$ can be synthesized from 4,6-dibromo-isatin by this hetero-ene reaction with $87 \%$ yield and $97 \%$ ee. Moreover, this method has the distinction of providing a good variety of substrates, facile procedure, and mild reaction conditions in relation to previously reported methods for ene-carbonyl reaction.

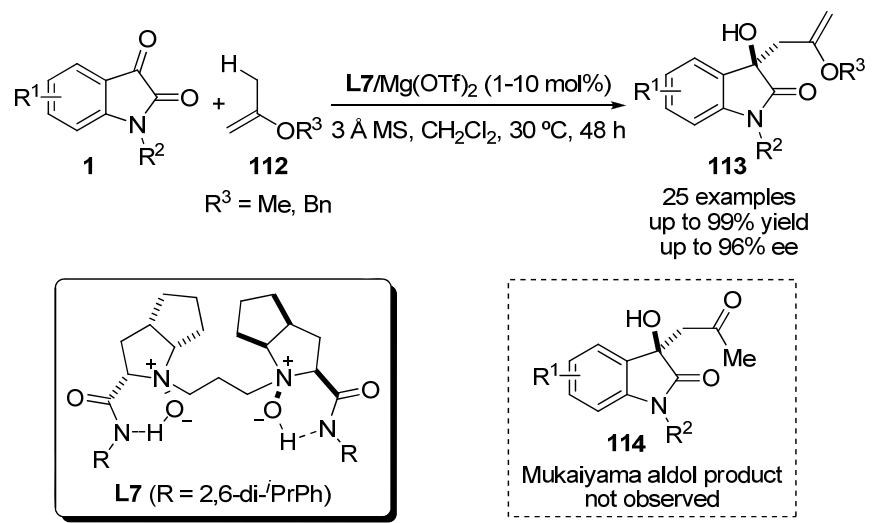

Scheme 36. Enantioselective addition of alkyl enol ethers 112 to isatin 1 via ene reaction.

\section{Metal catalyzed asymmetric synthesis of spirooxindoles}

The heterocyclic spirocyclic oxindoles are of great interest in organic synthesis because of their presence as core structure in natural products as well as their biological activity. ${ }^{[12,75]}$

Very recently, Shintani, Hayashi and co-workers have reported the application of phosphoramidite ligand L8 as an efficient ligand with palladium to diastereoselective synthesis of spirooxindole derivatives 116 through decarboxylative [4+2] cyclization of $\gamma$-methylidene- $\delta$-valerolactones 115 with isatins 1 (Scheme 37). ${ }^{[109]}$ The results have demonstrated that a bis(diphenylmethyl)amino group on phosphorus ligand can improve the yield and diastereoselectivity of the corresponding spirooxindoles (d.r. up to 99:1). According to the proposed mechanism by this group, nucleophilic addition of 1,4-zwitterionic species $\mathbf{1 1 7}$ to isatins 1 and then ring closure of intermediate $\mathbf{1 1 8}$ leads to desired products 116 in high yield with excellent diastereoselectivity (Scheme 38 ).

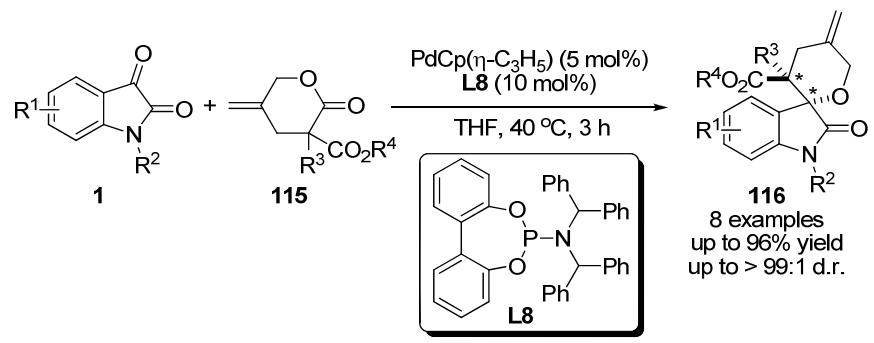

Scheme 37. Pd-catalyzed decarboxylative [4+2] cyclization of $\gamma$-methylidene- $\delta$ valerolactones 115 with isatin derivatives 1 .

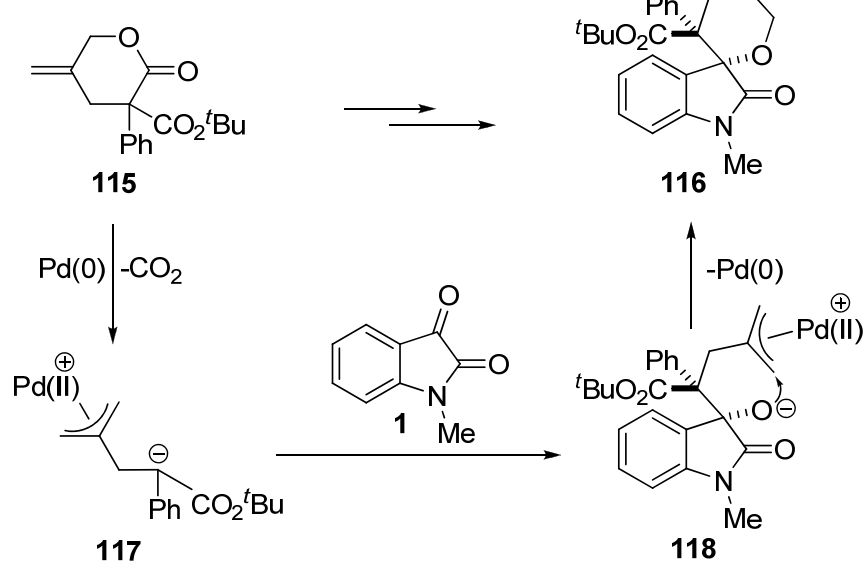

Scheme 38. Proposed catalytic cycle for the palladium-catalyzed decarboxylative cyclization of isatins 1 with compound 115 .

They have also explored the asymmetric variant of this catalyst to control the relative and absolute stereochemistry of the two contiguous stereocenters. By employing chiral phosphoramidite $\mathrm{L} 9$ as ligand at $0{ }^{\circ} \mathrm{C}$, the reaction gives the corresponding spirooxindoles with high yields and excellent stereoselectivity (d.r. $88: 12$ to $95: 5$, major isomer $73-87 \%$ ee) (Figure 17).

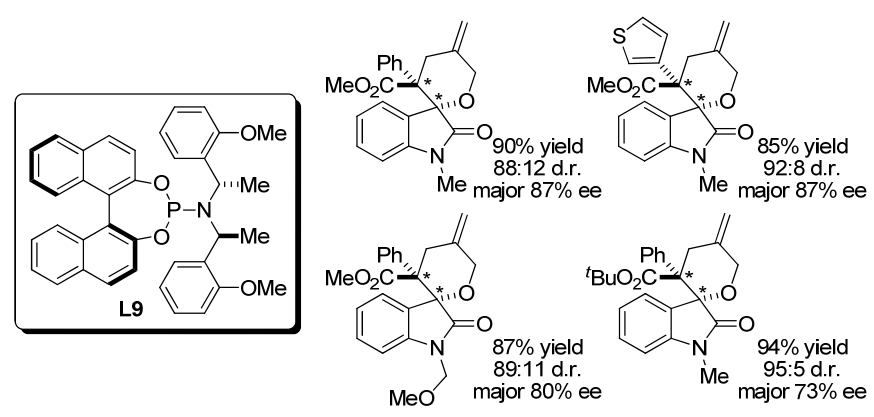

Figure 17. Asymmetric variant of Pd-catalyzed decarboxylative [4+2] cyclization of $\gamma$-methylidene- $\delta$-valerolactones $\mathbf{1 1 5}$ with isatin derivatives 1 .

\section{Outlook}

Isatin derivatives have gained an emergent interest in the last years in organic and medicinal chemistry since they constitute the backbone of a great number of interesting compounds especially those derived from 3-substituted-3-hydroxyindolin-2-ones as core structure. We have collected in this review the most representative examples in the field of organocatalysis and metal catalysis, giving to the reader a broad vision of their pivotal role in asymmetric catalysis as a current open area of research and as a strategic motif for the construction of appealing structures. In this sense, a number of research groups have invested efforts in the development of different reactions where isatin is a key substrate and herein these strategies have been described. The synthesis of important natural products has been also discussed showing the application of the developed catalytic methodologies. However, we believe that this field is still in its infancy and we will assist to the development of more reactions concerning this molecule and their application in industry in the very near future. 


\section{Acknowledgements}

We thank the Ministry of Science and Innovation (CTQ201019606-C02-01) and Aragon Government (E-10) for financial support of our research. R. H. and S. M. thank the Iranian Government for their fellowships and financial support.

Keywords: ((isatin · asymmetric catalysis · metal organocatalysis $\cdot$ oxindole $\cdot$ spirocycle))

[1] For reviews of oxindole alkaloids, see: a) C. Marti, E. M. Carreira, Eur. J. Org. Chem. 2003, 2209-2219; b) C. V. Galliford, K. A. Scheidt, Angew. Chem. Int. Ed. 2007, 46, 8748-8758; c) S. Peddibhotla, Curr. Bioact. Compd. 2009, 5, 20-38.

[2] For selected examples, see: a) R. B. Labroo, L. A. Cohen, J. Org. Chem 1990, 55, 4901-4904; b) P. Hewawasam, N. A. Meanwell, V. K. Gribkoff, S. I. Dworetzky, C. G. Boissard, Bioorg. Med. Chem. Lett. 1997, 7 1255-1260; c) Y. Koguchi, J. Kohno, M. Nishio, K. Takahashi, T. Okuda T. Ohnuki, S. Komatsubara, J. Antibiot. 2000, 53, 105-109; d) Y.-Q. Tang, I. Sattler, R. Thiericke, S. Grabley, X.-Z. Feng, Eur. J. Org. Chem. 2001, 261-267; e) T. Tokunaga, W. E. Hume, T. Umezome, K. Okazaki, Y. Ueki, K. Kumagai, S. Hourai, J. Nagamine, H. Seki, M. Taiji, H Noguchi, R. Nagata, J. Med. Chem. 2001, 44, 4641-4649; f) P. Hewawasam, M. Erway, S. L. Moon, J. Knipe, H. Weiner, C. G. Boissard D. J. Post-Munson, Q. Gao, S. Huang, V. K. Gribkoff, N. A. Meanwell, J. Med. Chem. 2002, 45, 1487-1499.

[3] a) Y. Kamano, H.-p. Zhang, Y. Ichihara, H. Kizu, K. Komiyama, G. R. Pettit, Tetrahedron Lett. 1995, 36, 2783-2784; b) S. Miah, C. J. Moody, I. C. Richards, A. M. Z. Slawin, J. Chem. Soc., Perkin Trans. 1 1997, 2405-2412.

[4] a) K. C. Nicolaou, X. Huang, N. Giuseppone, P. B. Rao, M. Bella, M. V. Reddy, S. A. Snyder, Angew. Chem. Int. Ed. 2001, 40, 4705-4709; b) K. C. Nicolaou, M. Bella, D. Y.-K. Chen, X. Huang, T. Ling, S. A. Snyder Angew. Chem. Int. Ed. 2002, 41, 3495-3499; c) K. C. Nicolaou, P. B. Rao, J. L. Hao, M. V. Reddy, G. Rassias, X. H. Huang, D. Y.-K. Chen, S. A. Snyder, Angew. Chem. Int. Ed. 2003, 42, 1753-1758; d) K. C Nicolaou, S. A. Snyder, N. Giuseppone, X. H. Huang, M. Bella, M. V. Reddy, P. B. Rao, A. E. Koumbis, P. Giannakakou, A. O'Brate, J. Am. Chem. Soc. 2004, 126, 10174-10182; e) K. C. Nicolaou, D. Y.-K. Chen X. H. Huang, T. Ling, M. Bella, S. A. Snyder, J. Am. Chem. Soc. 2004 126, 12888-12896.

[5] C. Takahashi, A. Numata, Y. Ito, E. Matsumura, H. Araki, H. Iwaki, K Kushida, J. Chem. Soc., Perkin Trans. 1 1994, 1859-1864

[6] A. Fréchard, N. Fabre, C. Péan, S. Montaut, M.-T. Fauvel, P. Rollin, I. Fourasté, Tetrahedron Lett. 2001, 42, 9015-9017.

[7] J. I. Jimenez, U. Huber, R. E. Moore, G. M. L. Patterson, J. Nat. Prod. 1999, 62, 569-572.

[8] a) J. Kohno, Y. Koguchi, M. Nishio, K. Nakao, M. Kuroda, R. Shimizu, T. Ohnuki, S. Komatsubara, J. Org. Chem. 2000, 65, 990-995; b) S. Lin, S. J. Danishefsky, Angew. Chem. Int. Ed. 2002, 41, 512-515; c) B. K Albrecht, R. M. Williams, Org. Lett. 2003, 5, 197-200; d) S. Lin, Z.-Q. Yang, B. H. B. Kwok, M. Koldobskiy, C. M. Crews, S. J. Danishefsky, J. Am. Chem. Soc. 2004, 126, 6347-6355; e) K. S. Feldman, A. G. Karatjas, Org. Lett. 2004, 6, 2849-2852.

[9] H. Suzuki, H. Morita, M. Shiro, J. Kobayashi, Tetrahedron 2004, 60, 2489-2495.

[10] a) K. Monde, K. Sasaki, A. Shirata, M. Takasugi, Phytochemistry 1991 30, 2915-2917; b) M. Suchý, P. Kutschy, K. Monde, H. Goto, N. Harada M. Takasugi, M. Dzurilla, E. Balentova, J. Org. Chem. 2001, 66, 39403947

[11] For some examples, see: a) R. R. Goehring, Y. P. Sachdeva, J. S Pisipati, M. C. Sleevi, J. F. Wolfe, J. Am. Chem. Soc. 1985, 107, 435443; b) A. K. Franz, P. D. Dreyfuss, S. L. Schreiber, J. Am. Chem. Soc. 2007, 129, 1020-1021; c) V. Schulz, M. Davoust, M. Lemarié, J.-F. Lohier, J. S. de Oliveira Santos, P. Metzner, J.-F. Brière, Org. Lett. 2007, 9, 1745-1748; c) R. R. Kumar, S. Perumal, Tetrahedron 2007, 63, 12220-12231.

[12] For important reviews about 3,3'-disubstituted oxindole structural motif, see: a) F. Zhou, Y.-L. Liu, J. Zhou, Adv. Synth. Catal. 2010, 352, 13811407 ; b) J. J. Badillo, N. V. Hanhan, A. K. Franz, Curr. Opin. Drug
Discovery Dev. 2010, 13, 758-776; c) A. Kumar, S. S. Chimni, RSC Adv. 2012, 2, 9748-9762

[13] a) O. Riant, J. Hannedouche, Org. Biomol. Chem. 2007, 5, 873-888; b) M. Bella, T. Gasperi, Synthesis 2009, 1583-1614.

[14] For selected reviews, see: a) B. Alcaide, P. Almendros, Angew. Chem. Int. Ed. 2003, 42, 858-860; b) B. List, Acc. Chem. Res. 2004, 37, 548557; c) C. Allemann, R. Gordillo, F. R. Clemente, P. H.-Y. Cheong, K. N. Houk, Acc. Chem. Res. 2004, 37, 558-569; d) S. Saito, H. Yamamoto, Acc. Chem. Res. 2004, 37, 570-579; e) R. Mahrwald (Ed.) Modern Aldol Reactions. Wiley-VCH, Weinheim, 2004, vols. 1 and 2; f) S. M. Dean, W. A. Greenberg, C.-H. Wong, Adv. Synth. Catal. 2007, 349, 1308-1320; g) M. Raj, V. K. Singh, Chem. Commun. 2009, 6687-6703; h) V. Bisai, A. Bisai, V. K. Singh, Tetrahedron 2012, 68, 4541-4580.

[15] G. Luppi, P. G. Cozzi, M. Monari, B. Kaptein, Q. B. Broxterman, C Tomasini, J. Org. Chem. 2005, 70, 7418-7421.

[16] For racemic examples of aldol reaction using isatin, see: a) E. M. Beccalli, A. Marchesini, T. Pilati, J. Chem. Soc., Perkin Trans. 11994 579-587; b) S. J.Garner, R. B. da Silva, A. C. Pinto, Tetrahedron 2002, 58, 8399-8412; c) T. Kawasaki, M. Nagaoka, T. Satoh, A. Okamoto, R. Ukon, A. Ogawa, Tetrahedron 2004, 60, 3493-3503; d) W.-B. Chen, Y.H. Liao, X.-L. Du, X.-M. Zhang, W.-C. Yuan, Green Chem. 2009, 11, 1465-1476.

[17] For a mechanistic study using proline, see: a) G. Chen, Y. Wang H. He, S. Gao, X, Yang, X. Hao, Heterocycles 2006, 68, 2327-2333; b) R. J. Corrêa, S. J. Garden, G. Angelici, C. Tomasini, Eur. J. Org. Chem. 2008, 736-744.

[18] G. Luppi, M. Monari, R. J. Corrêa, F. A. Violante, A. C. Pinto, B. Kaptein, Q. B. Broxterman, S. J. Garden, C. Tomasini, Tetrahedron 2006, 62, 12017-12024.

[19] G. Angelici, R. J. Corrêa, S. J. Garden, C. Tomasini, Tetrahedron Lett. 2009, 50, 814-817.

[20] a) H. Torii, M. Nakadai, K. Ishihara, S. Saito, H. Yamamoto, Angew. Chem. Int. Ed. 2004, 43, 1983-1986; b) A. I. Nyberg, A. Usano, P. M. Pihko, Synlett 2004, 1891-1896; c) P. M. Pihko, K. M. Laurikainen, A. Usano, A. I. Nyberg, J. A. Kaavi, Tetrahedron 2006, 62, 317-328.

[21] a) A. Cordova, W. Notz, C. F. Barbas III, Chem. Commun. 2002, 3024 3025; b) T. J. Dickerson, K. D. Janda, J. Am. Chem. Soc. 2002, 124 , 3220-3221; c) T. Darbre, M. Machuqueiro, Chem. Commun. 2003, 1090-1091; d) Y.-Y. Peng, Q.-P. Ding, Z. Li, P. G. Wang, J.-P. Cheng, Tetrahedron Lett. 2003, 44, 3871-3875; e) S. S. Chimni, D. Mahajan, Tetrahedron 2005, 61, 5019-5025.

[22] For further examples using prolinamide derivatives in this reaction, see: a) M. Kinsella, P. G. Duggan, C. M. Lennon, Tetrahedron: Asymmetry 2011, 22, 1423-1433; b) A. J. Pearson, S. Panda, Org. Lett. 2011, 13, 5548-5551; c) J. G. Hernández, V. García-López, E. Juaristi, Tetrahedron 2012, 68, 92-97.

[23] J.-R. Chen, X.-P. Liu, X.-Y. Zhu, L. Li, Y.-F. Qiao, J.-M. Zhang, W.-J. Xiao, Tetrahedron 2007, 63, 10437-10444.

[24] a) S. Bahmanyar, K. N. Houk, H. J. Martin, B. List, J. Am. Chem. Soc. 2003, 125, 2475-2479; b) B. List, L. Hoang, H. J. Martin, Proc. Natl. Acad. Sci. U.S.A. 2004, 101, 5839-5842; c) F. R. Clemente, K. N. Houk, J. Am. Chem. Soc. 2005, 127, 11294-11302.

[25] A. V. Malkov, M. A. Kabeshov, M. Bella, O. Kysilka, D. A. Malyshev, K. Pluhackova, P. Kocovsky, Org. Lett. 2007, 9, 5473-5476.

[26] S. Nakamura, N. Hara, H. Nakashima, K. Kubo, N. Shibata, T. Toru, Chem. Eur. J. 2008, 14, 8079-8081.

[27] For a recyclable process developed by the same authors using catalyst 12 introduced into Montmorillonite, see also: N. Hara, S. Nakamura, N. Shibata, T. Toru, Adv. Synth. Catal. 2010, 352, 1621-1624.

[28] Q. Guo, M. Bhanushali, C.-G. Zhao, Angew. Chem. Int. Ed. 2010, 49, 9460-9464.

[29] For a further work developed by the same research group, see: Q. Guo, J. C.-G. Zhao, Tetrahedron Lett. 2012, 53, 1768-1771.

[30] For a similar mechanism using a cinchona alkaloid-based urea catalyst, see: S. Allu, N. Molleti, R. Panem, V. K. Singh, Tetrahedron Lett. 2011, 52, 4080-4083.

[31] a) F. D. Popp, B. E. Donigan, J. Pharm. Sci. 1979, 68, 519-520; b) H. Pajouhesh, R. Parson, F. D. Popp, J. Pharm. Sci. 1983, 72, 318-321; c) K. C. Joshi , A. Dandia, S. Sanan, J. Fluorine Chem. 1989, 44, 59-72.

[32] A. Ricci, L. Bernardi, C. Gioia, S. Vierucci, M. Robitzer, F. Quignard, Chem. Commun. 2010, 46, 6288-6290. 
[33] M. Raj, N. Veerasamy, V. K. Singh, Tetrahedron Lett. 2010, 51, 21572159.

[34] C. Shen, F. Shen, H. Xia, P. Zhang, X. Chen, Tetrahedron: Asymmetry 2011, 22, 708-712.

[35] N. Hara, S. Nakamura, N. Shibata, T. Toru, Chem. Eur. J. 2009, 15, 6790-6793.

[36] F. Xue, S. Zhang, L. Liu, W. Duan, W. Wang, Chem. Asian J. 2009, 4, 1664-1667.

[37] T. Itoh, H. Ishikawa, Y. Hayashi, Org. Lett. 2009, 11, 3854-3857.

[38] For an additional example using the same catalyst 27, see: W.-B. Chen X.-L. Du, L.-F. Cun, X.-M. Zhang, W.-C. Yuan, Tetrahedron 2010, 66 , $1441-1446$.

[39] a) M. Hayashi, Y.-P. Kim, S. Takamatsu, A. Enomoto, M. Shinose, Y. Takahashi, H. Tanaka, K. Komiyama, S. Omura, J. Antibiot. 1996, 49 1091-1095; b) S. Takamatsu, Y.-P. Kim, A. Enomoto, M. Hayashi, H. Tanaka, K. Komiyama, S. Omura, J. Antibiot. 1997, 50, 1069-1072; c) M. Hayashi, M.-C. Rho, A. Enomoto, A. Fukami, Y.-P. Kim, Y. Kikuchi, T. Sunazuka, T. Hirose, K. Komiyama, S. Omura, Proc. Natl. Acad. Sci. U.S.A. 2002, 99, 14728-14733.

[40] M. Kitajima, I. Mori, K. Arai, N. Kogure, H. Takayama, Tetrahedron Lett. 2006, 47, 3199-3202.

[41] a) D. B. Damon, D. J. Hoover, J. Am. Chem. Soc. 1990, 112, 64396442; b) J. A. Erickson, J. I. McLoughlin, J. Org. Chem. 1995, 60, 16261631; c) C. Pesenti, F. Viani, ChemBioChem 2004, 5, 590-613.

[42] Y. Liua, J. Zhou, Chem. Commun. 2012, 48, 1919-1921.

[43] For selected reviews on Baylis-Hillman reaction, see: a) D. Basavaiah, A. J. Rao, T. Satyanarayana, Chem. Rev. 2003, 103, 811-892; b) D. Basavaiah, K. V. Rao, R. J. Reddy, Chem. Soc. Rev. 2007, 36, 15811588; c) G. Masson, C. Housseman, J. Zhu, Angew. Chem. Int. Ed. 2007 46, 4614-4628; d) V. Singh, S. Batra, Tetrahedron 2008, 64, 4511-4574; e) G.-N. Ma, J.-J. Jiang, M. Shi, Y. Wei, Chem. Commun. 2009, 54965514; f) V. Declerck, J. Martinez, F. Lamaty, Chem. Rev. 2009, 109, $1-$ 48; g) D. Basavaiah, B. S. Reddy, S. S. Badsara, Chem. Rev. 2010, 110 5447-5474

[44] a) Y. Iwabuchi, M. Nakatani, N. Yokoyama, S. Hatakeyama, J. Am. Chem. Soc. 1999, 121, 10219-10220; b) M. Shi, Y.-M. Xu, Angew. Chem. Int. Ed. 2002, 41, 4507-4510; c) K. Matsui, S. Takizawa, H. Sasai, J. Am. Chem. Soc. 2005, 127, 3680-3681; d) I. T. Raheem, E. N. Jacobsen, Adv. Synth. Catal. 2005, 347, 1701-1708; e) N. Abermil, G. Masson, J. Zhu, J. Am. Chem. Soc. 2008, 130, 12596-12597.

[45] a) M. Shi, L.-H. Chen, Chem. Commun. 2003, 1310-1311; b) M. Shi, L.H. Chen, C.-Q. Li, J. Am. Chem. Soc. 2005, 127, 3790-3800; c) Y.-H. Liu, L.-H. Chen, M. Shi, Adv. Synth. Catal. 2006, 348, 973-979.

[46] a) D. Basavaiah, T. K. Bharathi, V. V. L. Gowriswari, Tetrahedron Lett. 1987, 28, 4351-4352; b) P. V. Ramachandran, M. V. R. Reddy, M. T. Rudd, Chem. Commun. 2001, 757-758; c) M. V. R. Reddy, M. T. Rudd P. V. Ramachandran, J. Org. Chem. 2002, 67, 5382-5385.

[47] For racemic version of this reaction, see: a) S. J. Garden, J. M. S. Skakle, Tetrahedron Lett. 2002, 43, 1969-1972; b) Y. M. Chung, Y. J. Im, J. N. Kim, Bull. Korean Chem. Soc. 2002, 23, 1651-1654; c) S. C. Kim, S. Gowrisankar, J. N. Kim, Tetrahedron Lett. 2006, 47, 3463-3466.

[48] Y.-L. Liu, B.-L.Wang, J.-J.Cao, L. Chen, Y.-X. Zhang, C. Wang, J. Zhou, J. Am. Chem. Soc. 2010, 132, 15176-15178.

[49] X.-Y. Guan, Y. Wei, M. Shi, Chem. Eur. J. 2010, 16, 13617-13621.

[50] F. Zhong, G.-Y. Chen, Y. Lu, Org. Lett. 2011, 13, 82-85.

[51] C.-C. Wang, X.-Y. Wu, Tetrahedron 2011, 67, 2974-2978.

[52] J.-Y. Qian, C.-C.Wang, F. Shaa, X.-Y. Wu, RSC Adv. 2012, 2, 60426048.

[53] a) M. Bandini, A. Melloni, A. Umani-Ronchi, Angew. Chem. Int. Ed. 2004 43, 550-556; b) T. B. Poulsen, K. A. Jørgensen, Chem. Rev. 2008, 108 , 2903-2915; c) S.-L. You, Q. Cai, M. Zeng, Chem. Soc. Rev. 2009, 38 2190-2201; d) E. Marqués-López, A. Diez-Martinez, P. Merino, R. P. Herrera, Curr. Org. Chem. 2009, 13, 1585-1609; e) M. Bandini, A. Umani-Ronchi (Eds.) Catalytic Asymmetric Friedel-Crafts Alkylations. Wiley-VCH, 2009; f) V. Terrasson, R. M. de Figueiredo, J. M. Campagne, Eur. J. Org. Chem. 2010, 2635-2655.

[54] For non-asymmetric Friedel-Crafts-type reaction of indole with isatin, see: a) V. P. Kumar, V. P. Reddy, R. Sridhar, B. Srinivas, M. Narender, K. R. Rao, J. Org. Chem. 2008, 73, 1646-1648; b) G. Shanthi, N. V. Lakshmi, P. T. Perumal, ARKIVOC 2009, (x), 121-130.

[55] J. Deng, S. Zhang, P. Ding, H. Jiang, W. Wang, J. Li, Adv. Synth. Catal. 2010, 352, 833-838.
[56] P. Chauhan, S. S. Chimni, Chem. Eur. J. 2010, 16, 7709-7713.

[57] a) N. Ono (Ed.) The Nitro Group in Organic Synthesis. Wiley-VCH: New York, NY, USA, 2001; b) S. C. Bergmeier, Tetrahedron 2000, 56, 25612576

[58] Y. Alvarez-Casao, E. Marqués-López, R. P. Herrera, Symmetry 2011, 3, 220-245.

[59] a) C. Palomo, M. Oiarbide, A. Mielgo, Angew. Chem. Int. Ed. 2004, 43, 5442-5444; b) J. Boruwa, N. Gogoi, P. P. Saikia, N. C. Barua, Tetrahedron: Asymmetry 2006, 17, 3315-3326; c) C. Palomo, M. Oiarbide, A, Laso, Eur. J. Org. Chem. 2007, 2561-2574.

[60] For two racemic examples, see: a) M. N. Elinson, A. I. llovaisky, V. M. Merkulova, F. Barba, B. Batanero, Tetrahedron 2008, 64, 5915-5919; b) H. M. Meshram, P. Ramesh, A. S. Kumar, A. Swetha, Tetrahedron Lett. 2011, 52, 5862-5864.

[61] a) D. Seebach, F. Lehr, Angew. Chem. Int. Ed. Engl. 1976, 15, 505-506; b) M. Eyer, D. Seebach, J. Am. Chem. Soc. 1985, 107, 3601-3606; c) F. A. Luzzio, Tetrahedron 2001, 57, 915-945; d) J. M. Saa, F. Tur, J. Gonzalez, Chirality 2009, 21, 836-842.

[62] L. Liu, S. Zhang, F. Xue, G. Lou, H. Zhang, S. Ma, W. Duan, W. Wang, Chem. Eur. J. 2011, 17, 7791-7795.

[63] Y. Zhang, Z. J. Li, H. S. Xu, Y. Zhang, W. Wang, RSC Adv. 2011, 1, 389-392.

[64] M.-Q. Li, J.-X. Zhang, X.-F. Huang, B. Wu, Z.-M. Liu, J. Chen, X. D. Li, X.-W. Wang, Eur. J. Org. Chem. 2011, 5237-5241.

[65] P. S. Prathima, K. Srinivas, K. Balaswamy, R. Arundhathi, G. N. Reddy, B. Sridhar, M. M. Rao, P. R. Likhar, Tetrahedron: Asymmetry 2011, 22, 2099-2103

[66] A. Strecker, Ann. Chem. Pharm.1850, 75, 27-45.

[67] a) R. M. Williams, J. A. Hendrix, Chem. Rev. 1992, 92, 889-917; b) R. O. Duthaler, Tetrahedron 1994, 50, 1539-1650; c) J.-A. Ma, Angew. Chem. Int. Ed. 2003, 42, 4290-4299; d) C. Najera, J. M. Sansano, Chem. Rev. 2007, 107, 4584-4671; e) A. Perdih, M. S. Dolenc, Curr. Org. Chem. 2007, 1, 801-832

[68] M. S. Iyer, K. M. Gigstad, N. D. Namdev, M. Lipton, J. Am. Chem. Soc. 1996, 118, 4910-4911.

[69] a) H, Gröger, Chem. Rev. 2003, 103, 2795-2827; b) J. Wang, X. Liu, X. Feng, Chem. Rev. 2011, 111, 6947-698.

[70] P. Merino, E. Marqués-López, T. Tejero, R. P. Herrera, Tetrahedron 2009, 65, 1219-1234.

[71] For additional examples of nucleophilic addition to isatins derived ketimines, see: a) N. Hara, S. Nakamura, Y. Funahashi, N. Shibata, Adv. Synth. Catal. 2011, 353, 2976-2980; b) Q.-X. Guo, Y.-W. Liu, X.-C. Li, L.-Z. Zhong, Y.-G. Peng, J. Org. Chem. 2012, 77, 3589-3594; c) W. Yan, D. Wang, J. Feng, P. Li, D. Zhao, R. Wang, Org. Lett. 2012, 14, 2512-2515; d) J. Feng, W. Yan, D. Wang, P. Li, Q. Sun, R. Wang, Chem. Commun. 2012, 48, 8003-8005; e) F. Shi, G.-J. Xing, R.-Y. Zhu, W. Tan, S. Tu, Org. Lett. 2013, 15, 128-131; f) N. Hara, S. Nakamura, M. Sano, R. Tamura, Y. Funahashi, N. Shibata, Chem. Eur. J. 2012, 18, 9276-9280

[72] Y.-L. Liu, F. Zhou, J.-J. Cao, C.-B. Ji, M. Ding, J. Zhou, Org. Biomol. Chem. 2010, 8, 3847-3850.

[73] a) E. D. Cox, J. M. Cook, Chem. Rev. 1995, 95, 1797-1842; b) E. L. Larghi, M. Amongero, A. B. J. Bracca, T. S. Kaufman, ARKIVOC 2005, (xii), 98-153; c) J. Stöckingt, A. P. Antonchick, F. Wu, H. Waldmann, Angew. Chem. Int. Ed. 2011, 50, 8538-8564.

[74] a) J. E. Saxton (Ed.) Monoterpenoid Indole Alkaloids. Wiley Interscience: New York, 1983, Part 4; b) K. W. Bentley, Nat. Prod. Rep. 2004, 21, 395-424.

[75] For reviews, see: a) B. M. Trost, M. K. Brennan, Synthesis 2009, 30033025; b) N. R. Ball-Jones, J. J. Badillo, A. K. Franz, Org. Biomol. Chem. 2012, 10, 5165-5181. For an additional recent example, see: c) H.-P. Deng, Y. Wei, M. Shi, Org. Lett. 2011, 13, 3348-3351.

[76] S. Duce, F. Pesciaioli, L. Gramigna, L. Bernardi, A. Mazzanti, A. Ricci, G. Bartoli, G. Bencivenni, Adv. Synth. Catal. 2011, 353, 860-864.

[77] J. J. Badillo, A. Silva-García, B. H. Shupe, J. C. Fettinger, A. K. Franz, Tetrahedron Lett. 2011, 52, 5550-5553.

[78] M. Ordóñez, H. Rojas-Cabrera, C. Cativiela, Tetrahedron 2009, 65, 17 49 , and references therein cited.

[79] a) J.-A. Ma, Chem. Soc. Rev. 2006, 35, 630-636; b) P. Merino, E. Marqués-López, R. P. Herrera, Adv. Synth. Catal. 2008, 350, 11951208 , and references therein cited. 
[80] For a few racemic examples, see: a) A. Mustafa, M. M. Sidky, F. M. Soliman, Tetrahedron 1966, 22, 393-398; b) P. A. Gurevich, G. Z Akhmetova, A. T. Gubaidullin, V. V. Moskva, I. A. Litvinov, Russ. J. Gen. Chem. 1998, 68, 1501-1506; c) J. Shankar, K. Karnakar, B. Srinivas, Y. V. D. Nageswar, Tetrahedron Lett. 2010, 51, 3938-3939; d) L. Nagarapu, R. Mallepalli, U. N. Kumar, P. Venkateswarlu, R. Bantu, L. Yeramanchi, Tetrahedron Lett. 2012, 53, 1699-1700.

[81] L. Peng, L.-L.Wang, J.-F. Bai, L.-N. Jia, Q.-C. Yang, Q.-C. Huang, X.-Y Xu, L.-X. Wang, Tetrahedron Lett. 2011, 52, 1157-1160.

[82] N. V. Hanhan, A. H. Sahin, T. W. Chang, J. C. Fettinger, A. K. Franz, Angew. Chem. Int. Ed. 2010, 49, 744-747.

[83] E. G. Gutierrez, C. J. Wong, A. H. Sahin, A. K. Franz, Org. Lett. 2011, 13, 5754-5757.

[84] S. F. Martin, Acc. Chem. Res. 2002, 35, 895-904

[85] L. C. Wieland, E. M. Vieira, M. L. Snapper, A. H. Hoveyda, J. Am. Chem. Soc. 2009, 131, 570-576.

[86] Y.-H. Shi, Z. Wang, Y. Shi, W.-P. Deng, Tetrahedron 2012, 68, 36493653.

[87] a) B. Jiang, Z. Chen, X. Tang, Org. Lett. 2002, 4, 3451-3453; b) P. K. Dhondi, J. D. Chisholm, Org. Lett. 2006, 8, 67-69.

[88] a) E. F. DiMauro, M. C. Kozlowski, J. Am. Chem. Soc. 2002, 124 12668-12669; b) E. F. DiMauro, M. C. Kozlowski, Org. Lett. 2002, 4, 3781-3784; c) K. Funabashi, M. Jachmann, M. Kanai, M. Shibasaki, Angew. Chem. Int. Ed. 2003, 42, 5489-5492.

[89] P. Y. Toullec, R. B. C. Jagt, J. G. de Vries, B. L. Feringa, A. J. Minnaard, Org. Lett. 2006, 8, 2715-2718.

[90] R. B. C. Jagt, P. Y. Toullec, J. G. de Vries, B. L. Feringa, A. J. Minnaard, Org. Biomol. Chem. 2006, 4, 773-775.

[91] R. Shintani, M. Inoue, T. Hayashi, Angew. Chem. Int. Ed. 2006, 45, 3353-3356

[92] H. Lai, Z. Huang, Q. Wu, Y. Qin, J. Org. Chem. 2009, 74, 283-288.

[93] For an example of $\mathrm{Pd}-\mathrm{C}_{2}$-symmetric $\mathrm{N}$-heterocyclic carbene catalyzed arylboronation reaction of isatin, see: Z. Liu, P. Gu, M. Shi, P. McDowell, G. Li, Org. Lett. 2011, 13, 2314-2317.

[94] D. Tomita, K. Yamatsugu, M. Kanai, M. Shibasaki, J. Am. Chem. Soc 2009, 131, 6946-6948.

[95] For an example of $\mathrm{Cu}-\mathrm{N}$-heterocyclic carbene catalyzed asymmetric addition of arylboronates to isatin, see: R. Shintani, K. Takatsu, T. Hayashi, Chem. Commun. 2010, 46, 6822-6824.

[96] J. Itoh, S. B. Han, M. J. Krische, Angew. Chem. Int. Ed. 2009, 48, 63136316 .
[97] For selected examples of catalytic enantioselective ketone allylation, see: a) R. Wada, K. Oisaki, M. Kanai, M. Shibasaki, J. Am. Chem. Soc. 2004, 126, 8910-8911; b) J. G. Kim, K. M. Waltz, I. F. Garcia, D. Kwiatkowski, P. J. Walsh, J. Am. Chem. Soc. 2004, 126, 12580-12585; c) M. Wadamoto, H. Yamamoto, J. Am. Chem. Soc. 2005, 127, 1455614557; d) S. Lou, P. N. Moquist, S. E. Schaus, J. Am. Chem. Soc. 2006, 128, 12660-12661.

[98] a) I. S. Kim, M.-Y. Ngai, M. J. Krische, J. Am. Chem. Soc. 2008, 130, 14891-14899; b) I. S. Kim, S. B. Han, M. J. Krische, J. Am. Chem. Soc. 2009, 131, 2514-2520.

[99] For selected reviews on Hosomi-Sakurai reaction, see: a) A. Hosomi, Acc. Chem. Res. 1988, 21, 200-206; b) S. E. Denmark, J. Fu, Chem. Rev. 2003, 103, 2763-2793; c) S. E. Denmark, G. L. Beutner, Angew. Chem. Int. Ed. 2008, 47, 1560-1638.

[100] Z.-Y. Cao, Y. Zhang, C.-B. Ji, J. Zhou, Org. Lett. 2011, 13, 6398-6401.

[101] A racemic example $\mathrm{Bi}(\mathrm{OTf})_{3}$-catalyzed addition of allylsilanes to isatins has been reported; see: H. M. Meshram, P. Ramesh, B. C. Reddy, G. S. Kumar, Chem. Lett. 2011, 40, 357-359.

[102] N. V. Hanhan, N. R. Ball-Jones, N. T. Tran, A. K. Franz, Angew. Chem. Int. Ed. 2012, 51, 989-992.

[103] A. K. Franz, Curr. Opin. Drug Discovery Dev. 2007, 10, 654-671.

[104] N. V. Hanhan, Y. C. Tang, N. T. Tran, A. K. Franz, Org. Lett. 2012, 14, 2218-2221.

[105] T. Nakamura, S.-i. Shirokawa, S. Hosokawa, A. Nakazaki, S. Kobayashi, Org. Lett. 2006, 8, 677-679.

[106] M. L. Clarke, M. B. France, Tetrahedron 2008, 64, 9003-9031, and references therein cited.

[107] For some examples, see: a) K. Mikami, S. Matsukawa, J. Am. Chem Soc. 1993, 115, 7039-7040; b) E. M. Carreira, W. Lee, R. A. Singer, J. Am. Chem. Soc. 1995, 117, 3649-3650; c) R. T. Ruck, E. N. Jacobsen, J. Am. Chem. Soc. 2002, 124, 2882-2883; d) R. T. Ruck, E. N. Jacobsen, Angew. Chem. Int. Ed. 2003, 42, 4771-4774; e) K. Mikami, Y. Kawakami, K. Akiyama, K. Aikawa, J. Am. Chem. Soc. 2007, 129, 12950-12951; f) K. Aikawa, S. Mimura, Y. Numata, K. Mikami, Eur. J. Org. Chem. 2011, 62-65.

[108] K. Zheng, C. Yin, X. Liu, L. Lin, X. Feng, Angew. Chem. Int. Ed. 2011, 50, 2573-2577

[109] R. Shintani, S.-y. Hayashi, M. Murakami, M. Takeda, T. Hayashi, Org. Lett. 2009, 11, 3754-3756. 